\title{
Perspective of Plant Medicine in Therapy of Rheumatoid Arthritis
}

\author{
R. K. GAUTAM, K. ROY ${ }^{1}$, GAYATRI THAPA 1 , DISHAARORA², SMRITI PARASHAR ${ }^{3}$, BHUMIKA GURUNG ${ }^{4}$, L. DEB ${ }^{4 *}$ \\ Department of Pharmacology, MM School of Pharmacy, Maharishi Markandeshwar University, Sadopur, Ambala, \\ Haryana-134007, India, 'Department of Pharmacology, Himalayan Pharmacy Institute, Majhitar, Rangpo, Sikkim-737136, \\ India, ${ }^{2}$ Himalayan Institute of Pharmacy, Kala Amb, Himachal Pradesh-173030, India, ${ }^{3}$ Bioresources and Sustainable \\ Development (IBSD) - Sikkim Centre (An autonomous Institute of Department of Biotechnology, Government of India), \\ Tadong, Gangtok, Sikkim-795001, India
}

\section{Gautam et al.: Plant Medicine in Therapy of Rheumatoid Arthritis}

\begin{abstract}
Rheumatoid Arthritis is a systemic autoimmune disease characterized by chronic, inflammatory condition. The adverse effects of long-term use of presently available anti-arthritic or non-steroidal anti-inflammatory drugs are gastrointestinal symptoms, cardiovascular complications, renal impairment, myelosuppression etc. and this requires continuous monitoring and eventually increasing the cost of treatment. Thus complementary and alternative medicines may fulfill the demand for patients suffering from this disease. Moreover, herbal therapy has been safe and effective enough to treat rheumatoid arthritis. With these backgrounds, the present review includes different 37 plants reported for anti-arthritic or anti-inflammatory effect. Also enlisted 37 bioactive principals reported for anti-arthritic effect with their source, mechanism of action and commercial herbal products available in the market for treatment of rheumatoid arthritis. The compiled information regarding plants and their role in the treatment of rheumatoid arthritis will help to justify the use of plant-derived medicine in the therapy of rheumatoid arthritis in future.
\end{abstract}

Key words: Rheumatoid arthritis, anti-arthritic plants, herbal products, mechanism of action, medicinal plants, bioactive compounds

Out of 7 billion people in the world, World Health Organization (WHO) states that $0.3-1 \%$ of the population is suffering from Rheumatoid arthritis $(\mathrm{RA})^{[1]}$ and $20 \%$ of total population of India is afflicted by this disease ${ }^{[2]}$. Arthritis is a very common disorder that affected 50 million Americans in the year 2007-2009. According to the data provided by the National Health Interview Survey in 2007, 11.2 million, or nearly one in four aged adults with arthritis (24\%), also had heart disease. As per a cross-sectional study, in India $45 \%$ rheumatic diseases patients have co-morbidities such as hypertension, hypothyroidism and diabetes mellitus. Hence, imely diagnosis of associated co-morbid conditions is very much necessary for efficient management of rheumatic diseases ${ }^{[3]}$. The most common morbidity among adults with arthritis was heart disease. Among people with arthritis, $19 \%$ (9.0 million) also had chronic respiratory conditions and $16 \%$ (7.3 million) also had diabetes. Of the four conditions studied, stroke was the least common condition and affected 3.2 million people with

*Address for correspondence

E-mail: lokeshdeb@gmail.com

September-October 2020 arthritis ${ }^{[4]}$. As per WHO, in developed countries at least $50 \%$ RA patients are not capable of doing their fulltime job probably due to the disability arises within 10 year of onset of disease ${ }^{[5]}$. In India, $0.92 \%$ adults are suffering from RA. However, timely detection and aggressive treatment can prevent permanent disability, but that is not materialized in several cases. In India, around 20-40 new cases per 100 thousand population reporting every year and females are more susceptible for the disease. It was also reported that RA disease in females remains silent during pregnancy and onset of disease is observed after child delivery. Cigarette smoking, coffee and oral contraceptive pills reported as risk factor for developing of $\mathrm{RA}^{[6]}$.

RA is a systemic autoimmune disease characterized by

This is an open access article distributed under the terms of the Creative Commons Attribution-NonCommercial-ShareAlike 3.0 License, which allows others to remix, tweak, and build upon the work non-commercially, as long as the author is credited and the new creations are licensed under the identical terms

Accepted 23 December 2020

Revised 17 December 2020

Received 27 July 2020

Indian J Pharm Sci 2020;82(5):741-765 
chronic, inflammatory condition. The people suffering from RA are symptomized with pain, swelling, stiffness, destruction of cartilage and bone ${ }^{[1]}$. The four main symptoms of RA if present for 6 or more which confirms its diagnosis and this includes: morning stiffness in and around joints that lasts for one hour before maximal improvement is noted, swelling (arthritis) of soft tissue around three or more joints, swelling of proximal interphalangeal, metacarpophalangeal or wrist joint, symmetric arthritis ${ }^{[7]}$. Although the exact etiology is unknown but release of free radicals as a by-product of cellular metabolism may induce the generation of interleukins (IL) and Tumor necrosis factor- $\alpha$ (TNF- $\alpha$ ) from T-cells. These intermediates in response produces growth factors, cytokines and adhesive molecules on immune cells which causes inflammation and destruction of tissues ${ }^{[8]}$. Due to RA, the pathological changes observed are hyperplasia of synovial membrane, infiltration of inflammatory cells. These changes results in articular destruction and cartilage erosion ${ }^{[9]}$ This disease can be treated by either eliminating symptoms or slowing down its progression, which may lead to improvement of the quality of life $\mathrm{f}^{[10]}$.

Keeping the goal of treatment in mind, presently used drugs can vary which includes: over the counter drugs (acetaminophen, ibuprofen); Disease modifying antirheumatic drugs (methotrexate (MTX), penicillamine); Nonsteroidal anti-inflammatory drugs (NSAIDs) (diclofenac, ketoprofen) and biological agents (TNF- $\alpha$ blockers, rituxan). Though these therapeutic agents reduce infection and joint destruction, numerous side effects appear on prolonged use. The long-term use of these drugs leads to GI symptoms (ulcer, indigestion, and stomatitis), cardiovascular complications, hematologic toxicity, diarrhea, immune reactions, renal impairment, myelosuppression etc. This requires continuous monitoring which increases the cost of the treatment ${ }^{[2,7,11]}$.

The promising role as an anti-arthritic agent has been shown by many plants that are being used traditionally by various tribal and rural cultures worldwide. Herbal therapy has been safe and effective enough to treat RA and many are under scientific observation ${ }^{[12]}$.

Several mechanisms of action of plants to treat RA have been revealed with no observable side effects as compared to conventional therapy. The plants containing polyphenols exhibit their anti-rheumatic property by inhibiting inflammation either by modulating mitogenactivated protein kinases (MAPK) signaling pathway or by inhibiting Nuclear factor Kappa-Beta (NF-K $\beta$ ) pathway and Activator protein-1 (AP-1) transcription factors. They also inhibit the production of inflammatory cytokines and chemokine which further suppress the activity of Cyclooxygenase (COX) and inhibition of the inducible nitric oxide synthase (iNOs) further decreases the production of free radicals such as reactive oxygen and nitrogen species $^{[13,14]}$. Excessive production of nitric oxide (NO) which is a short-lived free radical produced from L-arginine is responsible for producing various inflammation and carcinogens at the site of inflammation which is inhibited by ethanolic extract of Alpinia officinarum rhizomes ${ }^{[15]}$. Flavonoids present in some plants like Clausena anisata, Kigelia africana, Melianthus comosus can inhibit the bio-synthesis of prostaglandins (PGs) which are the end products of immunologic responses in $\mathrm{RA}^{[16]}$. Flavonoids possess activity that inhibits inflammation and development of the induced granuloma. Quercetin like flavonoids blocks both COX and Lipoxygenase (LOX) pathways. Rutin and quercetin also possess anti-oxidant activity which suppresses the macrophage phagocytosis in $\mathrm{RA}^{[17]}$. Immune-suppressive effect is also exhibited by some plants like Tripterygium wilfordii which potentially inhibits the expression of pro-inflammatory cytokines, lymphocytes and synovial fibroblasts by inducing apoptosis in lymphocytes and synovial fibroblast and inhibition of proliferation ${ }^{[18]}$. Immunomodulatory effect exhibited by some plants like Amla and Shankhpushpi causes reduction in the induction of NO synthase and these plants suppress lymphocyte proliferation in response to adjuvant induced arthritis (AIA). They inhibit T-cell activation indicated by decreased lymphocyte proliferation. It proves that these plants have immunosuppressive effect mediated by T-cells ${ }^{[19]}$. Also, Camellia sinensis (green tea) inhibits TNF- $\alpha$, Interferon- $\gamma$, NF-K $\beta$, iNOS and COX by its active component Epigallocatechin-3-gallate. NO production is inhibited by Gingerol (Zingeber officinalis) and inhibits COX and LOX pathways thus inhibiting Prostaglandin-E2 (PGE2) synthesis. Hence, the various active constituents present in the plants aims at inhibiting pro-inflammatory cytokines which causes inflammation in the joints and cartilage destruction which are the distinguishing characteristics of $\mathrm{RA}^{[20]}$.

Therefore, we have reviewed and summed most of the herbal plants with their possible mechanism that helps treat RA with no long-term side effects as compared to conventional approach and thus improving RA patient's state of diseased condition. The important plants exerting an anti- arthritic activity are listed below with 
their respective roles as a therapy for RA.

\section{PLANTS USED IN THE THERAPY OF RA:}

\section{Adhatoda vasica nees:}

Athatoda vasica Nees belonging to the family Acanthaceae is an official drug in pharmacopoeia, India 1994. Pyrroloquinazoline alkaloid present in this plant possesses an anti-inflammatory property which was exhibited against adjuvant-induced experimental arthritis mice. Treatment with Adhatoda vasica extract (AVE) at different dose of $(50,100 \& 200) \mathrm{mg} / \mathrm{kg}$ significantly inhibited the progression of arthritis. Its administration reduced pro-inflammatory cytokines in serum and synovial tissues. It is observed that Toll like receptor (TLR-2) expression is suppressed in collagen induced arthritis in mice with the AVE administration. TLR-2 (component of innate immune system) is expressed on the macrophages and dendritic cell surfaces that is responsible for B and T-lymphocyte response generation under pathogenic incursion ${ }^{[21]}$.

\section{Ajuga bracteosa Wall ex Benth:}

Ajuga bracteosa belongs to the family Labiatae. Traditionally the plant is used for treatment of rheumatism, gout, palsy, diuretic, and also used as tonic, stimulant, astringent etc. in the Ayurveda and traditional healthcare systems of India. Phytochemically A. bracteosa has ajugarin I, lupulin A, withaferin A, reptoside and 6-deoxyharpagide ${ }^{[22]} .70 \%$ ethanolic extract of $A$. bracteosa was evaluated for anti-arthritic activity against turpentine oil, formaldehyde (acute non immunological models) and complete Freund's adjuvant (CFA) induced (Chronic immunological) arthritics in albino rats. In the experiment turpentine oil and formaldehyde induced acute non immunological inflammation that was significantly checked by A. bracteosa in a dose dependent manner. The CFA also induced chronic immunological arthritis characterized by marked oedema in hind paw that persisted for weeks (primary reaction). The primary reaction followed by oedema in contra-lateral and front paws along with appearance of arthritic nodules in ear and tail i.e. delayed systemic response (secondary reaction). The $\mathrm{X}$ ray pictures of CFA induced arthritic rats also showed signification reduction in inflammation by $A$. bracteosa extract that was comparable to standard aspirin treated rats $^{[23]}$.

\section{Aconitum carmechaeli Debeaux:}

Aconitum carmechaeli Debx is an indispensable medicinal plant having anti-inflammatory, antirheumatic and neurological indications ${ }^{[24]}$. Chemical analysis has revealed that tuberous roots of Aconitum contain the alkaloids: benzoylmecasonine, aconitine, hypaconitine, heteratisine, heterophyllisine, heterophylline, heterophyllidine, atidine, isotisine, hetidine, hetsinone and benzoylheteratisine, and the plant contains: heteratisine, heterophyllisine, atidine, isotisine, hetidine, hetsinone and benzoylheteratisine ${ }^{[25]}$. The mother and lateral root of $A$. carmichaelii Debx, called as "Chuanwu" (CW) and "Fuzi" in Chinese respectively, $\mathrm{CW}$ has an anti-arthritic effect in CFA induced arthritis rats $^{[26]}$ and methanol extracts of crude Aconitum roots have anti-inflammatory effects in inhibiting acid-induced vascular permeability and carrageen-induced hind paw edema in mice. The antiarthritic properties may be due to immune-depression and down-regulation of inflammatory cytokines, which may be a potential candidate for the treatment of $\mathrm{RA}^{[27]}$. Aconibal $^{\circledR}$ and MTX showed the potential beneficial effects in RA management ${ }^{[28]}$.

\section{Angelica sinensis:}

Angelica sinensis belongs to family Apiaceae. In China, A. sinensis has been used for the treatment of gynecological diseases, constipation, fever and hemorrhoids. The plant has also been used as a hematinic for nourishing blood, regulating menstruation, and relaxing bowels ${ }^{[29,30]}$. Over 70 compounds have been identified from $A$. sinensis, including essential oils such as ligustilide, butylphthalide and senkyunolide A, phthalide dimers, organic acids and their esters such as ferulic acid, polyacetylenes, vitamins and amino acids. Z-ligustilide (water insoluble and heat stable), among whichZ-butylidenephthalide and ferulic acid are thought to be the most biologically active components ${ }^{[31-33]}$. Ethyl acetate fraction from $A$. sinensis (Essential Amino Acids) inhibited IL-1 $\beta$ induced RA synovial fibroblasts; matrix metalloproteinases (MMPs1\&2), COX-2, and PGE2 production ${ }^{[34]}$. The combined action of sodium ferulate and polysaccharidic fraction of $A$. sinensis would prevent cartilage destruction in osteoarthritis and favor cartilage repair ${ }^{[35]}$. Calycosin is known to be one of the components of Angelica sinensis, which has been indicated to have an important role in the treatment of $\mathrm{RA}^{[36]}$.

\section{Alpina officinarum:}

It is known as lesser galangal and belongs to the family Zingiberaceae. It is an annual plant cultivated in 
Southern Asia. The rhizomes which are called galangal have been used as an anti-inflammatory, analgesic, stomachic and carminative since ages in traditional medicine. Its anti-inflammatory effect contributes in treating RA and osteo-arthritis. The rhizomes are dried underground and extracted using ethanol. Use of $80 \%$ of ethanolic extract in CFA- induced chronic arthritis; Carrageenan induced paw edema in Sprague- Dawley rats showed anti-inflammatory activity. However, the effect was exerted in a dose dependent manner. Long term arthritis has been the purported cause of mental disturbances which may be due to the abnormal expression of a C-p55, Fos proto-oncogene (c-Fos) antigen in the limbic system. It is known from literature that memory plays role in adaptation to pain. $200 \mathrm{mg} /$ $\mathrm{kg}$ and $500 \mathrm{mg} / \mathrm{kg}$ of the extracted when given orally for $23 \mathrm{~d}$ led to the reduction of the expression of c-Fos protein antigen in the hippocampus region of the brain of CFA injected rats. Thus it is evident that the extract not only inhibits inflammatory mediators but it can also assist the psychiatric condition by recovering c-Fos expression in the hippocampus region in RA condition $^{[15]}$.

\section{Barleria prionitis:}

The extract at a dose of $250 \mathrm{mg} / \mathrm{kg}$ showed most potent and significant $(\mathrm{p} \leq 0.05-0.01)$ paw edema inhibition which is supported by the results of body weight, biochemical parameters, motor incoordination and nociceptive threshold in CFA induced arthritis model ${ }^{[6]}$. The aqueous plant extract showed anti-inflammatory activity by inhibiting PGs synthesis ${ }^{[37]}$.

\section{Bryonia alba:}

Bryonia alba. L is a well-known herb for the treatment and cure of many ailments in central Europe ${ }^{[38]}$. B. alba in the form of a homeopathic formulation does exhibits promising results at various instance such as the xanthine oxidase and xanthine dehydrogenase activity ${ }^{[39]}$.

\section{Barringtonia racemosa Roxb.:}

It is a tree in the family Lecythidaceae found in coastal swamp forest of South Africa, India, Srilanka, Thailand. In the ayurvedic literature, its fruits are used for treatment of pain, inflammation and rheumatic conditions. Out of various constituents present in the plant, the Bartogenic acid (BA) isolated from the fruit has been shown to be effective when its evaluation was done in the CFA-induced arthritis in rats. This plant is also useful in as an anti-tumor, anti-nociceptive, antifungal etc. the extract obtained by cold maceration revealed that ethyl acetate fractions had potent anti-inflammatory activity. This extract was further fractionated on silica gel chromatography column whereby BA was isolated and its confirmation was done by chromatography and spectral data. Different dose of $\mathrm{BA}^{[2,5,10]} \mathrm{mg} / \mathrm{kg} / \mathrm{d}$ by mouth (p.o.) can protect the rat from arthritic lesions (primary and secondary). The secondary lesion is reduced due to potent suppression of cell mediated immunity in arthritic rat by BA. However, antiinflammatory effect is more than immune-suppressive effect as shown by reduced arthritic score. Reduced body weight during inflammation due to insufficient absorption of nutrients from intestine is ameliorated by the standard drug Diclofenac sodium and BA both. Also, white blood cell (WBC) count raised by IL-1 $\beta$ mediator in arthritic patients is normalized by BA. All these positive results to improve arthritic condition, manage pain and inflamed condition supports the use of $B$. racemosa and has led to its validation in ethnomedicinal use ${ }^{[40]}$.

\section{Crinum asiaticum:}

Crinum asiaticum L. belongs to the Amaryllidaceae family group of plants. Antinociceptive, antiinflammatory, and hepatoprotective effects of lycorine (a constituent of C. asiaticum) has been reported ${ }^{[41]}$. Antiinflammatory effect of $C$. asiaticum by the inhibition of iNOS and the release of PGE2, IL-6, and IL-8 has also been recorded ${ }^{[42]}$. The bulb of $C$. asiaticum is also useful in inflamed joints and sprains. Roasted bulb is used as rubefacient in rheumatism ${ }^{[43]}$. C. asiaticum leaf extract has potential anti-inflammatory effect to be recorded as plant-derived complementary medicine ${ }^{[44]}$. C. asiaticum Linn plant is used in Malaysia as a rheumatic remedy and to relieve local pain ${ }^{[45]}$.

\section{Curcuma longa:}

Turmeric and its curcumin-enriched extracts have been used for treating arthritis ${ }^{[46]}$. The curcumin metabolites may be responsible for the anti-inflammatory and antioxidant activities that reduce the symptoms of metabolic diseases including osteoarthritis ${ }^{[47,48]}$. The oral supplementation of curcumin at the dose of $110 \mathrm{mg} / \mathrm{ml} / \mathrm{kg} / \mathrm{d}$ has a potential to delay and improve joint abnormality and injury in Sprague-Dawley rats with collagen-induced arthritis CIA ${ }^{[49]}$. Curcumin also inhibited formaldehyde induced arthritis in rats at a dose of $40 \mathrm{mg} / \mathrm{kg}^{[50]}$. Curcumin given at $1200 \mathrm{mg}$ daily was effective in improving joint swelling, morning 
stiffness, and walking time ${ }^{[51]}$. Turmeric has shown to alleviate the pain of inflammation in diseases such as RA and psoriasis, overall promoting the immune system response of acute inflammation for its therapeutic abilities and alleviating chronic inflammation ${ }^{[52]}$. Cell culture studies, animal experiments and clinical trials indicate that curcumin may be potential as a therapeutic agent in diseases such as inflammatory bowel disease, pancreatitis, arthritis, and chronic anterior uveitis ${ }^{[33]}$. Turmeric extract containing curcuminoids prevents experimental $\mathrm{RA}^{[54]}$.

\section{Coriandrum sativum:}

Coriandrum sativum has been widely used in traditional medicine for treatment of RA and diabetes. Coriander seed possesses anti-arthritic activity, anti-inflammatory activity, antioxidant activity and hypolipidemic activity ${ }^{[55]}$. The anti-arthritic activity of coriander may be attributed to the modulation of proinflammatory cytokines in the synovium ${ }^{[56]}$. Cineole (one of the compounds of essential oil of coriander) and linoleic acid present in coriander possess anti-arthritic properties $^{[57]}$. A reduction in primarily macrophagederived pro-inflammatory cytokines, viz., IL-6 and IL-1 $\beta$, and the cytokine receptor TNF-R1 observed in the $C$. sativum hydro alcoholic extract treated group ${ }^{[58]}$.

\section{Clerodendrum serratum:}

Clerodendrum serratum have potent anti-rheumatic and antipyretic properties. The ethanolic root extract of $C$. serratum showed significant anti-inflammatory activity in carrageenan induced paw oedema in rats, and also in the cotton pellet model in experimental mice, rats and rabbits at concentrations of 50, 100 and $200 \mathrm{mg} / \mathrm{kg}^{[59]}$. The crude extracts of the aerial parts and roots of the plant C. serratum L. possess potential antirheumatic activity by supporting the folkloric use of the plant to treat various inflammatory conditions ${ }^{[60]}$. Root potion is used for chronic joints disease ${ }^{[61]}$. In carrageenan induced paw edema test $C$. serratum has shown significant suppression of edema ${ }^{[62]}$.

\section{Costus speciosus:}

Costus speciosus belongs to the family Zingeberaceae which is an erect plant of about $2.7 \mathrm{~m}$ tall with tuberous root and sub-woody stem. It has many uses such as antioxidant, anti-cancer, anti-inflammatory, hepatoprotective, adaptogenic etc. In one of the in vitro studies, the effect of costunolide on the production of pro-inflammatory mediators was targeted and the mechanism was stimulated with lipo-polysaccharides
(LPS) in a murine BV-2 cell culture. It was found that the level of inflammatory mediators such as TNF- $\alpha$, IL, IL-1, NOS and COX-2 in activated microglia was attenuated by costunolide through inhibition of NF-K $\beta$ and MAPkinase pathways. It proves that rheumatism due to inflammation can be treated by $C$. speciosus ${ }^{[63]}$. CFA induced arthritis model is the best available experimental model of RA. When this model was used against the methanolic extract of $C$. speciosus, the extract exhibited a significant anti- arthritic activity in a dose dependent manner where the progression of the RA was inhibited. The extract can successfully suppress the swelling of paws of rats in both acute and chronic phase of inflammation ${ }^{[64]}$.

\section{Cedrus deodara (Roxb.) Loud.:}

Cedrus deodara (Roxb.) Loud. belongs to the family Pinaceae and it is found in the Western Himalayas in Eastern Afganistan, Northern-Central India, South Western Tibet and Western Nepal. The oil and gum of Cedrus deodara have medicinal value in treating inflammation, dyspepsia, itching, elephantiasis, insomnia, hiccough, fever, bronchitis and piles. Especially leaves can be used to treat inflammation. The bitter wood has wide application in treating fever, rheumatism, piles, palsy, epilepsy, skin disease and urinary disorder. A review on Cedrus deodara revealed that the volatile oil extract of wood of this plant showed significant inhibition of carrageenan induced rat paw edema where the dose of 50 and $100 \mathrm{mg} / \mathrm{kg}$ body weight was given. It was also seen that the extract $(50 \mathrm{mg} /$ $\mathrm{kg}$ and $100 \mathrm{mg} / \mathrm{kg}$ body weight) showed significant inhibition of exudative- proliferative and chronic phase of inflammation ${ }^{[65]}$. The volatile oil extracted by steam distillation was used against AIA in rats. The secondary lesions developed in the ears, forelimbs and tails were scored ${ }^{[66]}$.

\section{Callicarpa macropohylla:}

The leaves root and flower of Callicarpa macropohylla has an anti-inflammatory property. Its leaves also have analgesic and anti-pyretic effect. It belongs to the family Verbenaceae. When in vitro anti-arthritic activity was assessed, it was observed that the protein (albumin) denaturation was inhibited significantly at different doses $(50 \mu \mathrm{g} / \mathrm{ml}, 100 \mu \mathrm{g} / \mathrm{ml}, 200 \mu \mathrm{g} / \mathrm{ml}, 400 \mu \mathrm{g} / \mathrm{ml}$ and $800 \mu \mathrm{g} / \mathrm{ml}$ showed $59.47 \%, 64.10 \%, 88.64 \%$, $98.21 \%$, and $130.52 \%$ protection respectively). The standard drug used was Diclofenac sodium. Inhibition of albumin denaturation by $C$. macrophylla was assessed because denaturation of the tissue protein 
takes place in arthritic diseases and is a cause of inflammation. It is reported that auto-antigen produced in certain arthritic diseases may be due to denaturation of proteins in vivo. Therefore, this plant can prevent protein denaturation and has significance in antiinflammatory drug development ${ }^{[67]}$. The in vivo test was also done using carrageenan as a phlogistic agent where the anti-inflammatory activity was evaluated by carrageenan paw edema method. It was found that the ethanolic and aqueous extracts of C. macrphylla contained carbohydrate, steroids, flavonoids and tannins. One or more of these phyto-constituents may inhibit the histamine, serotonin, PGs synthesis which plays the major role in inflammation ${ }^{[3]}$.

\section{Citrullus colocynthis:}

Citrullus colocynthis Schrad belongs to the family Cucurbitaceae. Fresh immature fruits and seeds can be taken for extraction where water can be used for the maceration. To obtain the alkaloid, dried plant part is macerated in ammonium hydroxide $(5 \mathrm{ml})$, ethanol $(10 \mathrm{ml})$, and di-ethyl ether $(30 \mathrm{ml})$. Then the mixture is separated by ether $(150 \mathrm{ml})$ and chloroform $(50 \mathrm{ml})$ and then treated with sulphuric acid. The base (precipitate) can be separated by adding ammonium hydroxide and the supernatant by adding chloroform following filtration. The $\mathrm{LD}_{50}$ is calculated to be 1 and $4 \mathrm{mg} / \mathrm{kg}$. Both phase of inflammation induced by carrageenan paw edema in rats was reduced which showed dose-dependent antiinflammatory activity. The mechanism of the extract is that the production of the pro-inflammatory cytokines like IL- 6 and IL- $1 \beta$ and COX-2 expression is decreased while it increases the anti-inflammatory cytokine IL-4 in carrageenan-injected paw edema. Hence the use of C. colocynthis is justified in treating $\mathrm{RA}^{[68]}$. One of the literature mentioned that the glycoside quercetin present in the fruit extract provided immunological protection henceforth the swelling in the paws caused by development of arthritis in rats was reduced ${ }^{[69]}$.

\section{Cinnamomum zeylanicum:}

C. zeylanicum belongs to a family Lauraceae. Its bark has medicinal values such as anti-inflammatory, analgesic, rheumatism and anti-pyretic effect as reported in many traditional literatures. Immune-modulatory effect is also possessed by cinnamon. The active constituent that exert the activity are gallic acid and polyphenols. When the C. zeylanicum bark (CPP) was administered orally with a dose of $50,100,200 \mathrm{mg} / \mathrm{kg} / \mathrm{d}$ for $9 \mathrm{~d}$ after $12^{\text {th }} \mathrm{d}$ of induction by adjuvant induced arthritic rats, there was significant dose-dependent improvement in the weight of rats. Also, serum TNF- $\alpha$ concentration got significantly decreased in CPP treated rats $(200 \mathrm{mg} /$ $\mathrm{kg} / \mathrm{d}$ ). It can be said that CPP inhibits the PGs synthesis and its release because CCP showed its effectiveness only in the $3^{\text {rd }} \mathrm{h}$ of its administration and it is known that carrageenan induced edema in rats is attributed by the release of histamine/serotonin followed by PGs. Hence, it can be concluded that C. zeylanicum does have anti-arthritic activity ${ }^{[70]}$.

\section{Celastrus paniculatus willd:}

It is one of the reputed plants in Ayurveda belonging to the family Celastraceae. The woody tree is India innate species and is distributed across Malaysia, China and Australia. Methanolic extract of flowers of C. paniculatus possess anti- inflammatory property along with analgesic activity. The herbal oil extracted from the seed by cold-pressed expression technique is used for treating rheumatism and gout as mentioned in the indigenous medicine system. The plant extract at a dose of $300 \mathrm{mg} / \mathrm{kg}$ exerts inhibitory effect on carrageenan induce paw edema in rats ${ }^{[71,72]}$.

\section{Euphorbia tirucalli:}

The plant is known for its medicinal value, such as antibacterial, antifungal, antiviral, anti-parasitic, anti-arthritic, anti-diabetic, antioxidant ${ }^{[73]}$. The plant is reported to be used traditionally in inflammatory disorders such as rheumatism and gout, to relieve pain in rheumatism and toothache, in nervine diseases, dropsy and deafness, and as a purgative ${ }^{[74]}$. Triterpenoids from E. tirucalli may be used as a potent natural antiinflammatory therapeutic agent for the treatment of arthritis like disorders ${ }^{[75]}$. The bio-polymeric fraction showed dose dependent anti-arthritic activity and also showed in vivo immune-modulatory capacity being a major component in inhibiting arthritis ${ }^{[76]}$.

\section{Lavandula stoechas L.:}

Lavandula stoechas L. belongs to family Lamiaceae. Phytochemical screening of extract of L. stoechas show presence of tannins, catechic tannins, flavonoids, sterols, coumarins, quinones, leucoanthocyans and mucilages compounds. Anti-inflammatory activities and sub-acute toxicity of hydro-ethanolic and polyphenols (flavonoid, tannin and mucilage) extracts from aerial part (branches, flowers and leaves) of L. stoechas was studied. The anti-inflammatory activity was evaluated by Carrageenan-Induced Rat Paw Edema method. The hydro-ethanolic extract of L. stoechas (5 and $10 \%)$ inhibited the inflammation induced by 
carrageenan in rats in a dose dependent manner. At dose of $10 \%$, L. stoechas produced a significant inhibition of inflammation at $74 \pm 7 \%$ compared to $69 \pm 10.3 \%$ for diclofenac at $1 \%$. Flavonoid and mucilage extracts showed significant effect in reduction of edema ${ }^{[13]}$.

L. stoechas essential oil is found rich in fenchone (37.0 \%) and camphor (27.3\%). L. stoechas is active against dermatophyte strains and showed potential anti-inflammatory activity at concentrations without affecting cell viability ${ }^{[77]}$.

Anti-inflammatory properties of L. stoechas extracts in two inflammatory experimental models: 2,4,6-Trinitrobenzenesulfonic acid model of rat colitis and the carrageenan-induced paw edema in mice were studied. L. stoechas extracts displayed immunomodulatory properties in vitro down-regulating different mediators of inflammation like cytokines and NO. They also showed anti-inflammatory effects in the TNBS model of colitis as evidenced by reduced myeloperoxidase activity and increased total glutathione content indicating a decrease of neutrophil infiltration and an improvement of the oxidative state. They also displayed anti-inflammatory effects in the carrageenaninduced paw edema in mice, since a significant reduction of the paw thickness was observed ${ }^{[77,78]}$.

\section{Moringa oleifera Lam.:}

It is an ornamental tree belonging to the family Moringaceae. Its seeds can be used to treat RA and the whole plant can be used as an anti-microbial agent, in venomous bites. The seeds powder is defatted with petroleum ether and then extracted with $95 \%$ ethanol. The phyto-constituents present are alkaloids, flavonoids, glycosides, tannins and terpenoids. The effect of $M$. oleifera on CFA induced arthritis in rats showed that the percentage weight reduction was significantly less. Similarly, when paw edema volume was measured, there was significant, very significant and highly significant decrease in the primary lesion in the M. oleifera 1 (100 mg) (MO1), M. oleifera 2 (200 mg) (MO2) and standard drug dexamethasone treated groups respectively. The serum parameters reflected the significantly increased level of Rheumatoid factor in arthritic diseased group which was reversed by MO1 and MO2 treatment for $21 \mathrm{~d}$. Also, TNF- $\alpha$, IL-1 and IL-6 was restored to nearly normal levels. This protective effect of the extract is thought to be brought about by the presence of flavonoid and antioxidants. Additionally, flavonoid prevents osteoporosis by increasing the bone mineral density. Furthermore, to explain the mechanism of action of the extract, the $M$. oleifera treatment interferes with the formation of either IL- 1 or IL- 6 or TNF- $\alpha$ and reduces the development of RA in rats due to adjuvant treatment ${ }^{[79]}$. In another study, the effect of the methanolic extract on turpentine oil induced arthritis (acute model) showed $70.25 \%, 90.46 \%$ and $91.33 \%$ at 125,250 and $500 \mathrm{mg} /$ $\mathrm{kg}$ p.o percent inhibition respectively ${ }^{[80]}$.

\section{Oryza sativa Linn. Njavara Rice:}

Oryza sativa L. (Njavara) belongs to the family Oryzae. It is grown exclusively in Kerala, South India. Since ancient times, and is used mainly for ayurvedic treatments. Njavara rice is used to treat arthritis, cervical spondylitis, muscle wasting, skin diseases, certain neurological problems circulatory, respiratory and digestive systems. Njavara kizhi is a specialized Ayurvedic therapy for treatment of paralysis, arthritis and neurological problems ${ }^{[81]}$. Njavara was studied for its anti-arthritic activity and anti-denaturation study by using bovine serum albumin (BSA) ${ }^{[82]}$. Denaturation of protein is one of the causes of $\mathrm{RA}^{[83,84]}$. When BSA is heated it undergoes denaturation and express antigens associated with type- III hypersensitivity reaction and that is related to diseases such as serum sickness, glomerulonephritis, RA and system lupus erythematous ${ }^{[85]}$.

The in vitro anti-arthritic activity was analyzed by BSA method. The sample Njavara rice extract showed $31.3,43.6,64.3,77.6 \%$ inhibition of denaturation of bovine serum at the concentration of 100, 250, 500 and $1000 \mu 1$ whereas standard diclofenac at $250 \mu 1$ showed $51.7 \%$ inhibition of denaturation activities. Production of auto-antigens in certain rheumatic diseases may be due to in vivo denaturation of proteins. Mechanism of denaturation probably involves alteration in electrostatic, hydrogen, hydrophobic and disulphide bonding. Ethanolic extract of O. sativa (Njavara) possess anti-arthritic activity due the presence of high number of bioactive compounds especially flavonoids. The higher oryzanol content, chemical indices, antioxidant and anti-inflammatory activity for Njavara compared with staple varieties corroborates with its medicinal use in Ayurveda ${ }^{[86]}$.

\section{Pinus lambertiana:}

Pinus lambertiana commonly known as the sugar pine or sugar cone pine is the tallest and massive pine tree and the longest cones of any conifer. Anti-arthritic activity of pinitol (PIN) was evaluated in AIA rat model. 
Pinitol is one of the major constituents and mainly isolated from $P$. lambertiana. PIN mimics the effects of insulin by acting downstream in the insulin signaling pathway. Inflammation was induced by injecting heat killed strain of Mycobacterium tuberculosis mixed in paraffin oil in the right hind paw of rats. PIN was administered orally at $1,2,4$ and $8 \mathrm{mg} / \mathrm{kg}$ once daily to treat the inflammation. The experiment showed a dosedependent decrease in edema and showed a suppression of mediators such as PGE2 and Leukotriene B4 (LTB4). PIN induced an inhibition of T cell mediated immune response causing suppression of CD4+ and CD8+ $\mathrm{T}$ cells by flow cytometer in arthritic animals. It also significantly lowered pro-inflammatory $\mathrm{T}$ helper type (Th)-1 cytokine levels in arthritic paw tissue homogenate supernatant viz. IL-2, IFN-c, and TNF-a with maximum inhibition at dose levels of $4 \mathrm{mg} / \mathrm{kg}$ p.o. and enhanced the production of anti-inflammatory (Th2) cytokines IL-4 and IL-5 estimated by cytometric bead array immunoassay. PIN at graded doses also significantly decreased the expression of IL-1b and nitric oxide levels showing significant inhibition of these parameters ${ }^{[87]}$.

\section{Piper nigrum:}

It is commonly called black pepper and is a flowering vine that belongs to Piperaceae family. It has a wide application ranging from spice, preservative, perfume to its medicinal uses. The medicinal use is brought about by the phenolic component Piperine. As this plant has shown in vitro inhibition of enzymes that helps in bio-synthesis of leukotriene, PGs, 5-lipoxygenase and $\mathrm{COX}-1$, it contributes the major role in treatment of RA. Specifically, IL6 and PGE2 production was inhibited when in vitro study was carried out taking IL1 $\beta$-stimulated RA fibroblast like synoviocytes (FLS) derived from arthritic patients. Also MMP13 collagenase enzyme was significantly inhibited in IL1B stimulated FLS ${ }^{[88]}$.

\section{Premna serratifolia linn.:}

It belongs to the family Verbenaceae and is widely distributed shrubs in deciduous forest of India and other parts of Asia. The woods P. serratifolia is useful in the treatment of arthritis. It has been reported in the indigenous system of medicine. The shrub can be used to treat many conditions such as weakness of limbs, headaches, cold and fever. It has also certain activity such as anti- coagulant, anti-inflammatory, anti-oxidant, anti-parasitic, in treating rheumatism and gonorrhea. Phyto constituents such as alkaloids, steroids, flavonoids, phenolic compounds, tannins and glycosides present in the shrub was revealed by the preliminary screening of the ethanol extract of the plant.

In the Freund's AIA model, treatment with $300 \mathrm{mg} / \mathrm{kg}$ body weight p.o of the plant extract improved the chronic swelling in multiple joints caused by influence of inflammatory cells and erosion of joint cartilage. These inflammatory cell mediators such as cytokines and interferon released during chronic inflammation are responsible for pain, destruction of bone leading to disability. Also the percentage inhibition of rat paw edema was produced to be $68.32 \%$ with ethanolic extract which is a close value obtained to that of a standard drug (indomethacin $=74.87 \%$ ) after $21 \mathrm{~d}$ of model induction. The extract can significantly increase the Red Blood Cells (RBC) count and body weight which is reduced in arthritic model. However, it can decrease the WBC count which gets increased in adjuvant model due to the release of IL-1B, in response to its release, the production of granulocyte and macrophage colony stimulating factors are also increased.

Therefore, the significant anti-arthritic activity is exhibited by the several phyto constituents particularly Iridoid glycosides present in this plant which proves it to possess medicinal value suitably ${ }^{[89]}$.

\section{Ranunculus sceleratus Linn.:}

Ranunculus sceleratus belong to family Ranunculaceae commonly known as blister buttercup, celery leaved crowfoot (English); jal dhaniyaa (folk). The whole plant is capable of promoting blood circulation by removing blood stasis, expelling cold, relieving swelling, and removing excessive heat from the liver and the gall bladder. It can also cure internal abscess, malaria, scrofula, snake or scorpion venom, and acute icteric hepatitis ${ }^{[90]}$.

Plants chemically constitute 5-hydroxy tryptamine, apigenin, apigenin $4^{\prime}-\mathrm{O}-\alpha-$ rhamnopyranoside, apigenin 7-O- $\beta$ glucopyranosyl-4'-O- $\alpha$-rhamnopyranoside, tricin 7-O- $\beta$-glucopyranoside, isoscopoletin, tricin, Protocatechuyl aldehyde, Protoanemonin ${ }^{[1]}$. $R$. sceleratus aerial are known to have anti-inflammatory activity investigated in rats in vivo and in vitro, nonpolar extract were able to inhibit eicosanoid production whereas polar extract enhanced the synthesis of 5(S)HETE ,LTB4 and 12(S)-HHTrE aerial part ${ }^{[92]}$.

\section{Randia dumetorum:}


It is a large thorny shrub belonging to the family Rubiaceae and is spread all over India upto $4000 \mathrm{ft}$. height. The phyto constituents present in this shrub include glycosides, triterpenoids, randianin, saponins and steroids. It is useful against bacteria, allergy, inflammation and algesia. Its fruit treat abscess, ulcers, inflammation and other skin related disorders. However, the main anti-arthritic activity is exhibited by the fruit of this shrub ${ }^{[93]}$. R. dumetorum at a dose of 100, 200 and $300 \mathrm{mg} / \mathrm{kg}$ reduces paw volume edema in rats which signifies the anti-inflammatory property of the plant. Arthritic score is decreased dose dependently from $d$ 12 onward of CFA induction in rats. In collagen induced rats, bone destruction was observed by radiological analysis and it was seen that there was development of narrowing of the spaces in the inter-tarsal joints. Also, the soft tissue was swollen and severe erosions of all joint space were observed. But the extract treated group of rats revealed the improvement in these abnormalities characterized by small erosions with rare asymmetric soft tissue swelling and minimum narrowing of the joint space. Histopathological results strengthens the anti-arthritic activity of this plant ${ }^{[94]}$.

\section{Santalum album:}

Santalum album Linn. belongs to family Santalaceae is commonly known as white sandalwood (English), safed chandan (Hindi) and srigandha (Sanskrit). It is found widely and cultivated in southern states of India. Traditionally, this plant is used in headache, fever and inflammation. The wood oil is used as diuretic, stimulant and disinfectant. Sandalwood contains a volatile oil 2.5-6\%. The main constituents of volatile oil are santalol, isovaleric aldehyde, santanone, santalone and tannic acid. The plant was evaluated for anti-inflammatory activity. The methanolic extract of wood was also evaluated for anti-inflammatory activities at various doses $(100,250 \& 500 \mathrm{mg} / \mathrm{kg})$ and compared with Diclofenac sodium $(7 \mathrm{mg} / \mathrm{kg})$ taken as standard. The extract showed maximum effect at $500 \mathrm{mg} / \mathrm{kg}^{[95]}$. Flavonoid extracted from the leaves of S. album for determining their anti-inflammatory and immunosuppressive activity ${ }^{[96]}$.

\section{Salvia mellifera:}

Salvia mellifera, is used as a topical preparation to relieve minor to moderate pain. The plant also contains diterpenoids such as rosmanol and carnosic acid that are analgesic and anti-inflammatory agents ${ }^{[97]}$.

\section{Sida rhombifolia Linn.:}

Sida rhombifolia Linn. belong to the family Malvaceae. The Sida species is one of the most important families of medicinal plants in India. Plants aerial part extracts were screened for various parameters of anti-arthritic activity, such as adjuvant-induced arthritis, motor performance, mean distance travelled, and histopathological study. It showed that the polar constituents (ethanol and aqueous extracts) of the plant $S$. rhombifolia were useful in the treatment of arthritis ${ }^{[98]}$. Anti-oxidant potential of $S$. rhombifolia extracts for $30 \mathrm{~d}$ on AIA in experimental rats was investigated. The altered levels of haematological parameters were reverted to near normal levels; especially the elevated rate of erythrocyte sedimentation was significantly reduced by $S$. rhombifolia extracts in experimental rats. Oral administration of root and stem of S. rhombifolia extracts significantly increased the levels of thiobarbituric acid reactive substances and activities of catalase and glutathione peroxidase and decreased the levels of reduced glutathione and superoxide dismutase activity in arthritis induced rats ${ }^{[99]}$.

\section{Swertia chirata Buch.Ham:}

Swertia chirata Buch.Ham (Fam. Gentianaceae) is widely used in India to treat fever, malaria and liver diseases ${ }^{[100]}$. In addition, it is reported to have antiinflammatory activity ${ }^{[101]}$. Xanthone derivatives like mangostin, isomangostin and mangostin triacetate are known to possess significant anti-inflammatory activities. The total xanthones of Swertia species produce significant CNS stimulant action ${ }^{[102,103]}$.

Anti-inflammatory effect of xanthone derivative (1, 5-dihydroxy-3,8-dimethoxy xanthone) of $S$. chirata (SC-I) in acute, sub-acute and chronic experimental models in male albino rats was studied ${ }^{[100]}$.

Aqueous extract of $S$. chirayita stem was studied on the anti-inflammatory cytokines balance in primary joint synovium of adjuvant-induced arthritic mice. The level of pro-inflammatory cytokines was found elevated in the joint synovium of arthritic mice in comparison to normal joints. Administration of $S$. chirayita extract in varying doses through the oral route, a dose dependent $(0,11.86$ and $23.72 \mathrm{mg} / \mathrm{kg}$ body weight) reduction of TNF- $\alpha$, interleukin- $1 \beta$, (IL- $\beta$ ) and interferon- $\gamma$, (IFN- $\gamma$ ) and elevation of Interleukin- 10 (IL-10) was observed in the joint homogenates of arthritic mice. Interleukin-6 (IL-6) was not down regulated in joint homogenate of arthritic mice at the dose $11.86 \mathrm{mg} / \mathrm{kg}$ but at higher doses $(23.72$ and $35.58 \mathrm{mg} / \mathrm{kg})$ significant reduction 
was observed. The aqueous extract was found to possess two polar compounds, amerogentin and mangiferin but was devoid of swerchirin, chiratol, methyl swetianin, and swertanone. Mangiferin possess potent antiinflammatory property and presumed its presence in the aqueous extract of S. chirayita is responsible for reducing TNF- $\alpha$, IL-1 $\beta$, IL-6, and IFN- $\gamma$ and/or elevating IL-10 in the joint homogenates of arthritic mice on $\mathrm{d} 12^{[104]}$.

\section{Syzyium cumini:}

Syzygium cumini (Family: Myrtaceae) is a folklore plant traditionally indicated to treat various inflammatory disorders. Phytochemical screening of the ethyl acetate and methanolic extracts of S. cumini seed used in this study revealed that the crude extract contained alkaloids, amino acids, flavonoids, glycosides, phytosterols, saponins, steroid, tannins and triterpenoids. S. cumini seeds can also have various medicinal values such as anti-inflammatory, antidiabetic and analgesic activities and also for central nervous system activity ${ }^{[105]}$. Anti-rheumatic activity of petroleum ether extract of $S$. cumini stem bark at the doses of $50,500,750,1000 \mathrm{mg} / \mathrm{kg}$ on CFA AIA has been studies in rats. The treatment is assessed by measuring the paw volume, body weight, arthritic index, and rheumatoid factor. The result showed that the extract inhibited the CFA induced arthritis in dose dependent manner and this effect was more significant $(\mathrm{p}<0.05)$ with $1000 \mathrm{mg} / \mathrm{kg}$ dose. The standard drugs Indomethacin $(10 \mathrm{mg} / \mathrm{kg})$, dexamethasone $(0.1 \mathrm{mg} / \mathrm{kg})$ also produce significant anti-rheumatic effect in rats and are compared with test drug ${ }^{[106]}$. The anti-arthritic effect of oral administration of methanolic extract of S. cumini seeds (SME) on Freund's complete adjuvant (FCA) induced arthritis has been studied in rats. The treatment is assessed by measuring the paw volume and by using various hematological parameters like hemoglobin ( $\mathrm{Hb}$ ) content, total RBC count, WBC count and erythrocyte sedimentation rate (ESR). The extract inhibited the CFA induced arthritis in a dose dependent manner and this effect was more significant $(p<0.001)$ with $500 \mathrm{mg} / \mathrm{kg}$ dose. SME showed significant effect in preventing the rat paw edema volume and improved the RBC count, $\mathrm{Hb}$ level and the ESR to a near normal level when compared to CFA induced arthritis rats. In addition, SME also significantly decreased the WBC count in CFA induced arthritis rats. Administration of extract improved the body weight significantly when compared to CFA induced arthritis rats. The anti- arthritic effect of SME was compared to that of standard drug Indomethacin ${ }^{[107]}$.

\section{Tripterygium wilfodii:}

Tripterygium wilfodii Hook (TWH), an herbal plant growing mainly in South China, was described in ancient Chinese medical texts and has been used widely in China for treatment of joint pain ${ }^{[107]}$. Tripterygium wilfordii Hook F (TwHF) is effective for treating active RA patients and is superior to placebo and sulphasalazine according to American College of Rheumatology Criterion (ACR) 20, 50, and 70. TwHF is superior to conventional synthetic Diseasemodifying Anti-rheumatic Drugs (DMARDs) such as MTX, leflunomide, sulphasalazine ${ }^{[108]}$. Extracts of T. wilfordii Hook suppress both immune and inflammatory responses and also effectively treat a number of models of autoimmune disease ${ }^{[109]}$. The ethanol/ethyl acetate extract of TWHF shows therapeutic benefit in patients with treatment-refractory $\mathrm{RA}^{[110]}$. Extracts of TwHF, in combination with MTX reduced swollen and tender joint counts, shortened the duration of morning stiffness, decreased the ESR, and decreased the level of C-reactive protein and rheumatoid factor ${ }^{[111]}$.

\section{Urtica dioica:}

Urtica dioica (Urticaceae) is also called Stinging Nettle. In a folklore medicine, it has been used to treat arthritis and rheumatism and as a diuretic agent. It has been called a potent medicinal plant based upon the information on traditional knowledge, ethno biological and ethno medicinal issues and also by identification and studies of pharmacologically important molecules of this plant. In RA the inflammatory events are inhibited by the leaf extracts of $U$. dioica by switching TH1 derived responses to Th- $2^{[112]}$. When the experiment was carried out, it was found that the $50 \mathrm{mg}$ dried powdered extract of the plant combined with $50 \mathrm{mg}$ of Diclofenac sodium had similar effect to $200 \mathrm{mg}$ of Diclofenac sodium alone. Hence, $U$. dioica reduces the NSAID dose by $50 \%^{[113]}$. Recent studies conclude that RA is elevated by NF-K $\beta$ which is responsible for enhanced expression of many pro-inflammatory gene products. The different cell lines (the human T-cell line Jurkat, the macrophage cell line monomac6, the epithelial cell line HeLa) were treated with the extract that inhibited the NF-kB activation ${ }^{[114]}$.

\section{Withania somnifera:}

Withania somnifera has been used in Unani Medicine 
as an anti-inflammatory and to treat rheumatism beside other ailments. Administration of $W$. somnifera root powder $(600 \mathrm{mg} / \mathrm{kg})$ to the arthritic rats significantly decreased the severity of arthritis by effectively suppressing the symptoms of arthritis and improving the functional recovery of motor activity and radiological score $^{[115]}$. WS extract inhibited liposaccharide induced synthesis of pro-inflammatory cytokines (TNF- $\alpha$, IL-1 $\beta$ and IL-12) in peripheral and synovial fluid mononuclear cells from RA subjects in vitro ${ }^{[116]}$. The WS extract also showed inhibitory effects on collagenase activity that may be useful in joint disease treatment ${ }^{[117]}$. Oral administration of Withenia somnifera Linn., root powder showed the anti-arthritic effect in adjuvant induced arthritic rats ${ }^{[118]}$.

\section{Zingiber officinale:}

Ginger is obtained from rhizomes of Zingiber officinale. The plant belongs to Zingiberaceae family. It has been widely used as a medicinal herb and spice ${ }^{[119]}$. Because of containing phytochemical ingredients and as a beneficial therapeutic agent, $Z$. officinale has been contributing against a broad range of diseases like asthma, diabetes, stroke and constipation ${ }^{[58,120]}$. Anti-inflammatory effect of ginger was scientifically proven $^{[121]}$.

The activity of $Z$. officinale as an anti-inflammatory agent was investigated in rats ${ }^{[122]}$. Experimental rats were treated with aqueous extract of $Z$. officinale either orally or intraperitoneally daily for $4 \mathrm{w}$. Though at low dose ginger did not reduce PGE2 concentrations, at high doses it significantly lowered PGE2 levels. Therefore, ginger could reduce inflammation associated with RA. Both in vivo and in vitro experiments were conducted to evaluate the effect of 6-gingerol as an inflammatory agent $^{[123]}$.
Monosodium urate crystal-induced inflammation was developed in mice as a model of gouty arthritis. They found that 6-gingerol significantly reduced the lysosomal enzymes level as well as inhibiting lactate dehydrogenase and acid phosphate. These results show clear indication of anti-inflammatory activity of this ginger phytochemical.

\section{Zingiber zerumbet:}

The rhizomes of Zingiber zerumbet belong to family Zingiberaceae. The essential oil of the rhizomes of $Z$. zerumbet was reported for the acute and chronic antiinflammatory activities using the carrageenan-induced paw edema and cotton pellet-induced granuloma tests, respectively. The effect of the essential oil on inflammatory and non-inflammatory mediated pain was also assessed using the formalin test. Essential oil of Z. zerumbet, at doses of 30,100 , and $300 \mathrm{mg} / \mathrm{kg}$, was administered intra-peritoneally to rats. The substance exhibited significant anti-inflammatory activity both in acute and chronic animal models. The essential oil also inhibited inflammatory and non-inflammatory mediated pain when assessed using the formalin test ${ }^{[124]}$. Antiinflammatory constituents of Z.zerumbetlikezerumbone, 3-O-methyl kaempferol, kaempferol-3-O-(2, 4-diO-acetyl- $\alpha$-L-rhamnopyranoside), and kaempferol3-O-(3,4-di-O-acetyl- $\alpha$-L-rhamnopyranoside) were isolated from the rhizome of $Z$. zerumbet ${ }^{[125]}$. The antiinflammatory activity of zerumbone, a natural cyclic sesquiterpene isolated from Z. zerumbet Smith was investigated using carrageenan-induced paw edema and cotton pellet-induced granuloma tissue formation test in mice. It was demonstrated that intraperitoneal administration of zerumbone at a dose of 5, 10, 50 and $100 \mathrm{mg} / \mathrm{kg}$ produced significant dose-dependent inhibition of paw edema induced by carrageenan. It was also demonstrated that zerumbone at similar

TABLE 1: LIST OF THE PLANT -DERIVED ACTIVE PRINCIPLE REPORTED FOR ANTI-INFLAMMATORY EFFECT

\begin{tabular}{|c|c|c|c|c|}
\hline $\begin{array}{l}\text { SL } \\
\text { NO. }\end{array}$ & NAME OF COMPOUNDS & PLANT SOURCE & MECHANISM OF ACTION & REFERENCE \\
\hline 1 & Pyrroloquinazoline & $\begin{array}{l}\text { Adhatoda } \\
\text { vasica Nees }\end{array}$ & $\begin{array}{l}\text { Toll like receptor (TLR-2) suppression in collagen of } \\
\text { arthritic mice }\end{array}$ & 18 \\
\hline 2 & $\begin{array}{l}\text { Ajugarin-I, Lupulin-A, } \\
\text { Withaferin-A, Reptoside \& } \\
\text { 6-deoxyharpazide }\end{array}$ & $\begin{array}{l}\text { Ajuga bracteosa } \\
\text { Wall }\end{array}$ & Inhibition of COX-1 and COX-2 enzymes & 19 \\
\hline 3 & Aconitines, Benzoylaconine & $\begin{array}{l}\text { Aconitum } \\
\text { carmechaeli } \\
\text { Debeaux }\end{array}$ & $\begin{array}{l}\text { Inhibitory effects on- acute inflammation (by inhibiting } \\
\text { increased vascular permeability) and proliferative } \\
\text { inflammation (granulation tissue) }\end{array}$ & 24 \\
\hline 4 & Calycosin & $\begin{array}{l}\text { Angelica } \\
\text { sinensis }\end{array}$ & $\begin{array}{l}\text {-Inhibition of inflammatory mediator- interleukin-6 } \\
\text { receptor (IL-6R) }\end{array}$ & 32,33 \\
\hline & Ferrulic acid & & $\begin{array}{l}\text {-Inhibition of IL- } B \text {, matrix metalloproteinase (MMP-1), } \\
\text { COX-2 \& PGE-2 production }\end{array}$ & \\
\hline
\end{tabular}


www.ijpsonline.com

5 Diarylheptanoids

$6 \quad$ Triterpenoid

Iridoid glycosides, Barlerin, Acetyl barlerin

$7 \quad$ Cucurbitacin glucoside

8

Bartogenic acid

9

Lycorine

10

Curcumin

11

12

Apigenin-7-0-glucuronide flavonoid

prionitis asiaticum sativum serratum $\begin{array}{ll}\text { Diarylheptanoids } & \begin{array}{l}\text { Alpina } \\ \text { officinarum }\end{array}\end{array}$

-Inhibitors of the production of multi-functional NO by

iNOS which is involved in inflammation

-Reduction of abnormal expression of c-Fos antigen

protein in the hippocampus which causes mental

disturbances in long term arthritis

-Inhibits histamine release from mast cells and exert

anti-inflammatory effect

-inhibition of COX pathway(PGE-2 synthesis) and

inhibition of LOX enzymes(leukotriene B4)

Inhibits LT-B4 and 5-HETE (mediators of inflammation)

and modulates corticosteroid secretion

126

Barringtonia -Inhibits IL-1B (mediator of inflammation) and normalizes racemosa Roxb. raised WBC count in RA

-Reduction of C-reactive protein

Crinum inhibition of inducible nitric oxide synthase (iNOS) and

Curcuma longa

the release of PGE2, IL-6, and IL-8

-Down-regulates the activity of COX-2, LOX, iNOS and

NFK-B

-inhibition of TNF-a, IL-6, monocyte chemo-attractant protein

-Down-regulates mitogen-activated and janus kinases.

Coriander Reduction in pro-inflammatory cytokines such as IL-6, IL-

Clerodendrum

Stigmasterol, Arbusculin A, Costus Specioic acid

speciosus

Deodarone, , isohemacholone, atlantone Cedri

B-sitosterol, ursolic acid, Callicarpa luteolin and apigenin macropohylla

Quercetin

17

Celastrine, celapanine, Celapagine

19

Triterpinoids

Flavonoids and mucilage

\section{Citrullus} colocynthis

Cinnamomum zeylanicum

Celastrus paniculatus Euphorbia tirucalli

Lavandula stoechas

Moringa oleifera
$1 \mathrm{~B}$ and cytokine receptor-TNF-R1

-Acts during early phase of acute inflammation by inhibiting early release of histamine, serotonin and prostaglandins

-Weak anti-proliferative effect by preventing formation of collagen fibre and suppression of mucopolysaccharides

-Reduction of inflammatory markers i.e. CRP, IL-6

-Inhibition of NFK-B and MAP-kinase pathways

-Inhibits COX-2 pathway

Inhibition of COX enzyme causing inhibition of prostaglandin synthesis

-Controls the production of auto-antigens as this auto-antigen production in arthritis causes protein denaturation

-Inhibits histamine and prostaglandin synthesis

Decreases IL-6, IL-1B and COX-2 expression whereas increases anti-inflammatory cytokine like IL-4

Inhibits prostaglandin synthesis and its release

Decreases TNF- $a$ concentration

Inhibition of prostaglandin synthesis and IL-1B

Diminishes CRP level and inhibits IL-1, IL-6 and TNF- $\alpha$

Inhibits arthritis related joint destruction

-Synergistic action of flavonoid and mucilage on COX pathway inhibition -Immunomodulatory action- down-regulates inflammatory cytokines such as nitric oxide and cytokines

-Prevents denaturation of proteins which causes inflammatory arthritic condition 
www.ijpsonline.com

Flavonolignans

[tricin 4 -0-(threo-b-

22 guaiacylglyceryl)] \& [tricin 4 -0- (erythro-bguaiacylglyceryl)]

23

Pinitol

24

Piperine

25

Iridoid glycoside

Phytol,B-sitosterol, Stigmasterol, Ranunculine

27

Randianin

Triterpenoids

Randioside A

28

Santanone, santalone

Diterpenoids-Rosmanol,

29 Carnosic acid and tanshinone

B-Phenethylamine,

$\mathrm{N}$-methyl-B-

Sida

Ranunculus

sceleratus

Randia

dumetorum

phenethylamine, vasicinol, rhombifolia

vasicinone, vasicine.

Xanthone derivative $(1$, 5-dihydroxy-3,8-dimethoxy xanthone), Mangostin, Mangiferin Isomangostin and Mangostin triacetate

Rutin, B-sitosterol, quercetin

33

Triptolide, tripdiolide and triptonide

Tripterygium wilfodii

Carvacrol, carvone Urtica dioica

chlorogenic acid, phaselic acid, rutin

35

Withanolides, withaferinA, Withania withanolide D

36

6-gingerol

Sesquiterpene-Zerumbone.

Santalum

album somnifera

Salvia mellifera -Inhibition of TRP channels

-inhibition of the production of IL-17 and chemokines and down-regulates COX-2

-inhibition of induction of reactive oxygen species by inhibiting iNOS.

98

-Reduction of TNF- $a$, interleukin-1B, (IL-B) and

Swertia chirata interferon- $\gamma,($ IFN- $\gamma)$ and elevation of Interleukin- 10

(IL-10)

-Elevation of anti-inflammatory mediator- IL-10

-Increases the plasma protein such as fibrinogen, $a$ and $B$ globulins and obscure the disease

-Controls the IL-1B release

-Inhibits TNF- $a$ and IL-1

-Decreases C-reactive protein and rheumatoid factor

108,111

Inhibits NFK-B activation, AP-1 activation

$1,12,133$

Inhibits cytokines expression and eicosanoids formation

-Inhibits TNF-alpha, IL-1beta and IL-12

116

-Inhibitory effect on collagenase activity

-inhibits prostaglandin synthesis at high dose

Pragasam et al. 2011.

-Reduces lysosomal enzymes

Suppresses granulomatous tissue formation 
TABLE 2: LIST OF THE PLANT MARKETED HERBAL PRODUCT AVAILABLE FOR THE TREATMENT OF RHEUMATOID ARTHRITIS

SI. Name of marketed/

No. commercial product

1. Shigru

Flexibility 60

2. Capsules Bottle

3. Osteoseal 60 capsules bottle

Allen A28

Rheumatism Drop

4.

Allen homoeo \& herbal products Itd., Allen Estate, Krishnapur Road, Kolkata-700 102, India

GNC triflex fast acting

5. (supports joint health and flexibility - 120 tablets)

Apres flex GNC nutraceuticals, 300 6th Avenue 14th Floor Pittsburgh, PA 15222 United States.

Organic India private limited, Office no -03, Ground floor,

Uppals Plaza
Delhi - 110025

The Himalaya Drug Company, Makali, Bengaluru 562162.

Organic India private limited, Office no -03, Ground floor Uppals Plaza M6, Jasola District Center, New Delhi - 110025

Withania somnifera (Ashwagandha)

Tinospora cordifolia (Guruchi)

Ocimum sanctum (Rama Tulsi)

Cissus quadrangularis (Harjor)

Moringa oleifera (Sahijan)

Asparagus racemosus (Shatavari)

Rhus toxicodendron (poison ivy)

Arnica Montana (mountain tobacco)

Ruta gravelens (rue)

Gaultheria procumbans (eastern teaberry)

Hypericum perforatums (perforate St John's

wort)

Guaiacum officinale

(roughbark lignum-vitae)

Curcuma longa (Turmeric)

Boswellia serrreta (Shallaki)

Sesamum indicum L. (Til Tail)

Dhanwantaram

6. thailam pre-post natal Kama ayurveda product ltd., India treatment oil

Rubia cordifolia (Manjeeth)

Elettaria cardamomum (Elayachi)

Withania somnifera (Ashwagandha)

Phyllanthus emblica(Amla)

7. Cissus tvs0038

TVS biotech., 4 355, Ramagounder, Thottam , Annadanapatti, Salem - 636002, Tamil Nadu, India

Cissus quadrangularis (Harjor)

Dr Ortho Combo Pack

8. of Ayurvedic Oil 120ml Dr Ortho Mouza Rampur Jattan, Kala-Amb, \& Ayurvedic Capsules Distt. Sirmour, Himachal Pradesh - 173030 30

Ortho Balm and Deemark Health Care Pvt Ltd., 4-H-1, Garg Tower, Netaji Subhash Place,

Pitam Pura, Delhi - 110034, India.

Deemark

Naturoman Near Nandan Cinema Bahind Yadu Nutmeg Pure and Natural Essential Oil

Biotrex rose hip

11. Biotrex Hotel Meerut 250002

Biotrex 1106-1107, Matrix Tower, Near Divya Bhaskar, Corporate Road, Prahlad Nagar, Ahmedabad 380015 Gujarat, INDIA

New Life Laboratories Pvt. Ltd., 16, Bal Vihar Road Ghora Nakkas, Bhopal-462001, Madhya Pradesh, India
Mentha piperita (Peppermint)

Cinnamomum camphor (Kapoor)

Pinus roxburghii (Sarla)

Linum usitatissimum (Flax)

Gaultheria procumbens (gandhpura)

Mentha arvensis (pudina)

Cinnamomum tamala (tejpatha)

Myristica fragrans (Nutmeg)

Rosa canina (The seed pods of roses)

Bryonia alba (wild hop)

Colchicum autumnale (meadow saffron)

Guaiacum sanctum (roughbark

lignum-vitae)

stellaria media (chickweed) 
13. Rumartho

14. Rhuma gel

15. Yograj guggulu

16.

Mahayograj Guggulu 40 tabs
Shree Baidyanath Ayurved Bhawan Pvt. Ltd., 1, Gupta Lane, Kolkata 700006, India

Shree Baidyanath Ayurved Bhawan Pvt. Ltd., 1, Gupta Lane, Kolkata 700006, India

Shree Baidyanath Ayurved Bhawan Pvt. Ltd. 1, Gupta Lane, Kolkata 700006, India
Vanda Roxburghii (Rasna)

Commiphora wightii (Guggulu)

Withania somnifera (L.) Dunal (Ashwagandha)

Eucalyptus globules (southern blue gum)

Withania somnifera (L.) Dunal (Ashwagandha)

Asparagus racemosus (Shatavari)

Curcuma amada (mango ginger)

Sesamum indicum L. (Til Taila)

Plumbago zeylanica (Ceylon leadwort)

Piper longum (Long Pepper)

Embelia Ribes (Vidang)

Cuminum cyminum (Cumin)

Commiphora wightii (Guggulu)

Cedrus deodara (Devdaru)

Piper chaba (Chui Jhal)

Elettaria cardamomum (Elayachi)

Tribulus terrestris (Gokhru)

Cyperus rotundus(Nagarmotha)

Cinamomum tamala (Indian cassia)

Zingiber officinale (Ginger)

Ficus religiosa ( Pipal)

Piper retrofractum (Balinese long pepper)

Piper longum (Long Pepper)

Plumbago indica (Leadwort)

Ferula assa-foetida (Ferula)

Apium graveolens(Celery)

Shree Baidyanath Ayurved Bhawan Pvt. Ltd., Foeniculum vulgare (Fennel flower) 1, Gupta Lane, Kolkata 700006, India

Nigella sativa (Kajonji)

Holarrhena pubescens (Indrajav)

Embelia Ribes (Vidang)

Picrorhiza kurrooa (Kutki)

Annona squamosa (Atis)

Commiphora wightii (Guggulu)

Blend of Terminalia bellirica, Terminalia

chebula, Phyllanthus emblica (Triphala) 
www.ijpsonline.com

17. Maharasandi kwath

18. Dabur rheumatil oil

19. Organic navara red rice

20. Himalaya rumalaya tablets

Artho care - joint pain Artho Care, 3/10, Kirti Nagar Ind. Area, New relief

Delhi - 110015, India

Dr. Willmar Schwabe India Pvt. Ltd., A-36, Sector 60,

22. Guaiacum mt

23. Aamvatari ras

Uttar Pradesh, India.

\author{
Pluchealanceolata (Rasna) \\ Alhagicamelorum (Javasa) \\ Sidacordifolia (Bariyara) \\ Ricinuscommunis (Erand) \\ Cedrusdeodara (Devdaru) \\ Curcuma zedoaria (Kachur) \\ Acorus calamus (Bach) \\ Adhatodavasica (Adusa) \\ Tribulus terrestris (Gokhru) \\ Withania somnifera (Ashwagandha) \\ Aconitum heterophyllum (Atish) \\ Cassia fistula (Amaltas) \\ Asparagus racemosus (Shatavari) \\ Ficusreligiosa (Pipal) \\ Barleriaprionitis (Kat-sareya) \\ Coriandrum sativum (Dhaniya) \\ Zingiber officinale (Ginger) \\ Terminalia chebula (Harad) \\ Piper retrofractum (Chavya) \\ Cyperusscariosus (Nagarmotha) \\ Boerhaaviadiffusa (Punarnava) \\ Tinospora cordifolia (Giloy) \\ Argyreiaspeciosa (Vidhara) \\ Foeniculum vulgare (Sounf) \\ Solanum surattense (KateliChhoti) \\ Solanum indicum (KateliBadi) \\ Syzygium aromaticum (Lavang) \\ Mentha $\times$ piperita (Pudina) \\ Eucalyptus L'Hér (Neelgiri) \\ Commiphora wightii (Guggulu) \\ Gaultheria (Gandhapuro) \\ Zingiber officinale (Ginger) \\ Plectranthus amboinicus \\ (Njavara) \\ Moringa oleifera Lam. \\ (Shigru, Drumstick) \\ Tinospora cordifolia (Thunb.) Miers (Guduchi) \\ Curcuma longa (Haldi) \\ Boswellia serrata (Shallaki) \\ Ocimum Sanctrum/Ocimum tenuiflorum (Tulsi) \\ Guaiacum officinale \\ (roughbark lignum-vitae) \\ Blend of Terminalia bellirica, Terminalia \\ chebula (Harad), Phyllanthus emblica \\ (Triphala) \\ Plumbago indica (Chitrakmool) \\ Commiphora wightii (Guggul) \\ Ricinus communis (Erand Tail)
}


24.

Peedantak oil

25. Singhnad guggul

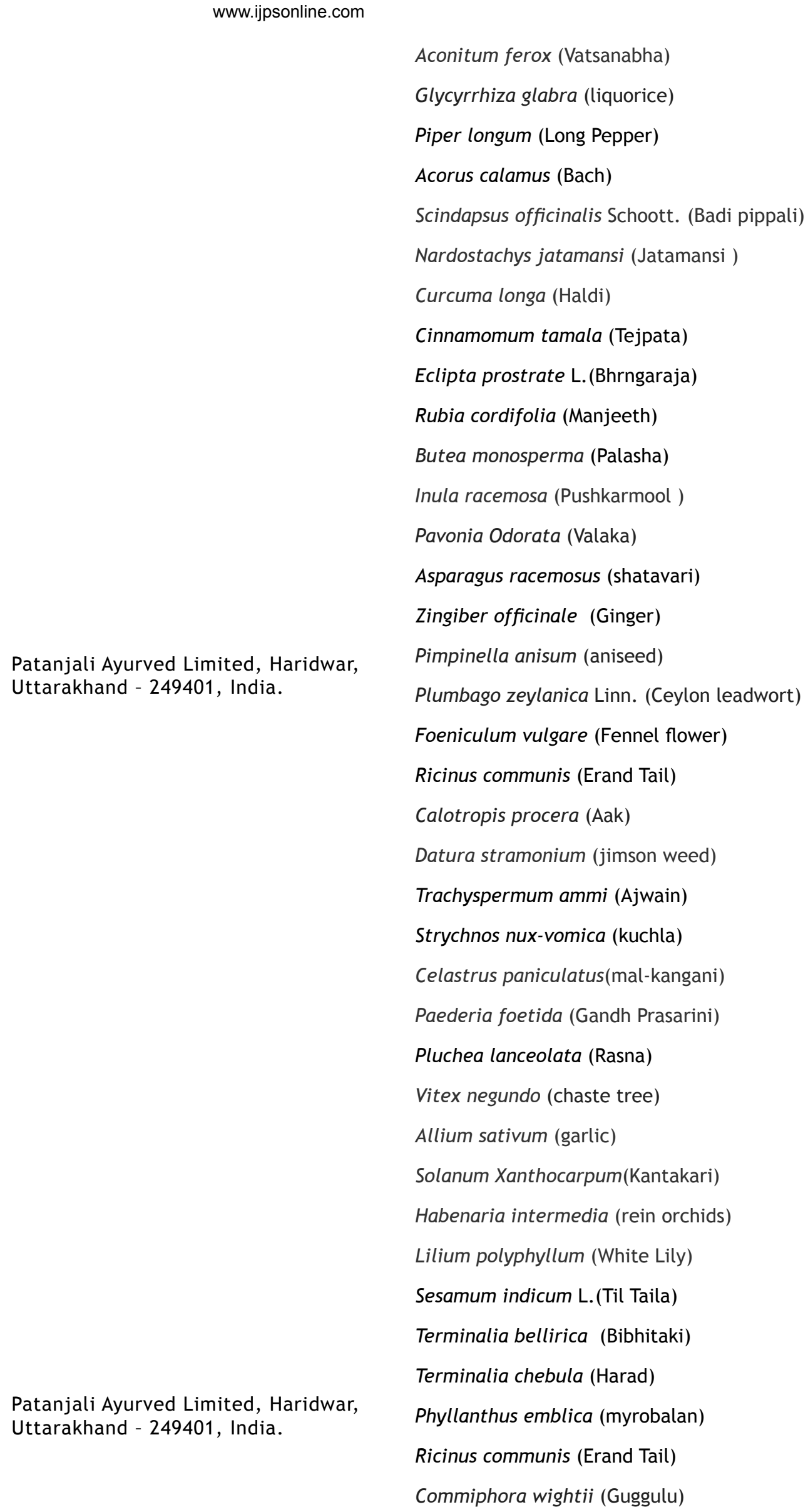


26. Divya peedantak vati

Patanjali Ayurved Limited, Haridwar, Uttarakhand - 249401, India.
27. Ajmodadi churna
Patanjali Ayurved Limited, Haridwar, Uttarakhand - 249401, India.
Commiphora wightii (Guggulu)

Colchicum luteum (meadow saffron)

Withania somnifera (L.) Dunal (Ashwagandha)

Asphaltum (Shilajeet shuddha)

Strychnos nux-vomica (kuchla)

Cyperus scariosus (Nagarmotha)

Pluchea lanceolata (Rasna)

Vitex negundo(Nirgundi)

Boerhaavia diffusa (punarnava mool)

Trigonella foenumgraecum (methi)

Operculina turpethum (nisoth)

Asparagus racemosus (shatavari)

Cissus quadrangularis (harjord)

Curcuma longa (Haldi)

Zingiber officinale (Ginger)

Picrorhiza kurrooa (Kutki)

Trachyspermum ammi (Ajwain)

Corallium rubrum (praval pishti)

Vitex nigundo (Nirgundi)

Tinospora cordifolia (giloy)

Apium graveolens(Celery)

Embelia ribes Burm.f. (VaiVidang)

Cedrus deodara (Devdaru)

Plumbago indica (ChitrakMool)

Rock salt (Sendha Namak)

Terminalia chebula (Chhoti Harad)

Argyreia nervosa (vidhara )

Piper nigrum L.(Kali Mirch)

Piper longum (Long Pepper)

Glycine max (soya bean) 
www.ijpsonline.com

28. Bala taila $100 \mathrm{ml}$

Patanjali Ayurved Limited, Haridwar, Uttarakhand - 249401, India.

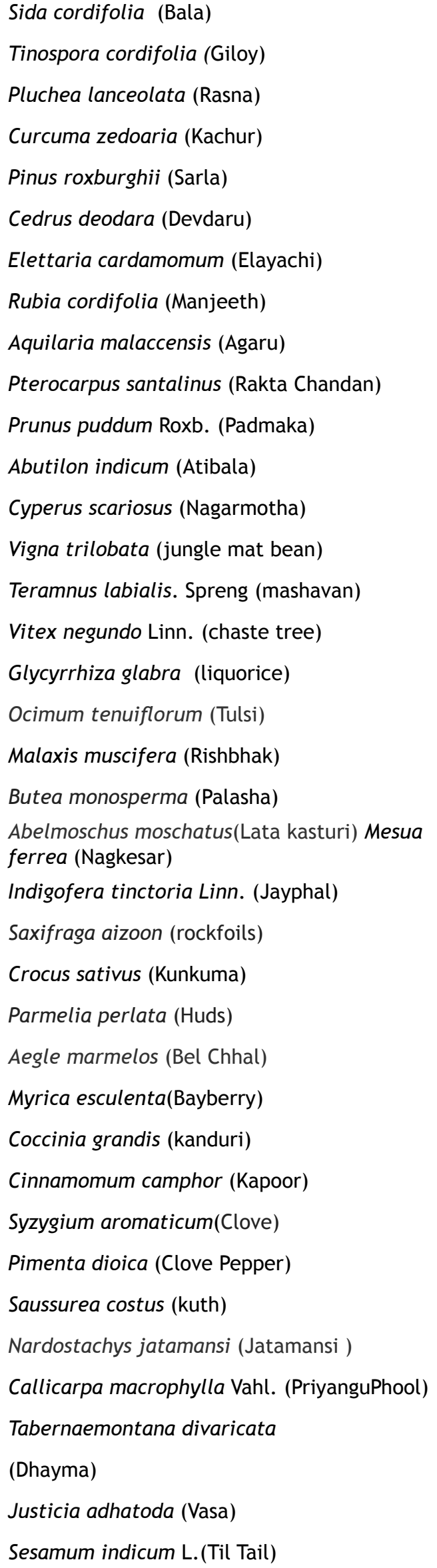


www.ijpsonline.com

29. Mahanarayan taila $100 \mathrm{ml}$
Shree Baidyanath Ayurved Bhawan Pvt. Ltd., 1, Gupta Lane, Kolkata 700006, India

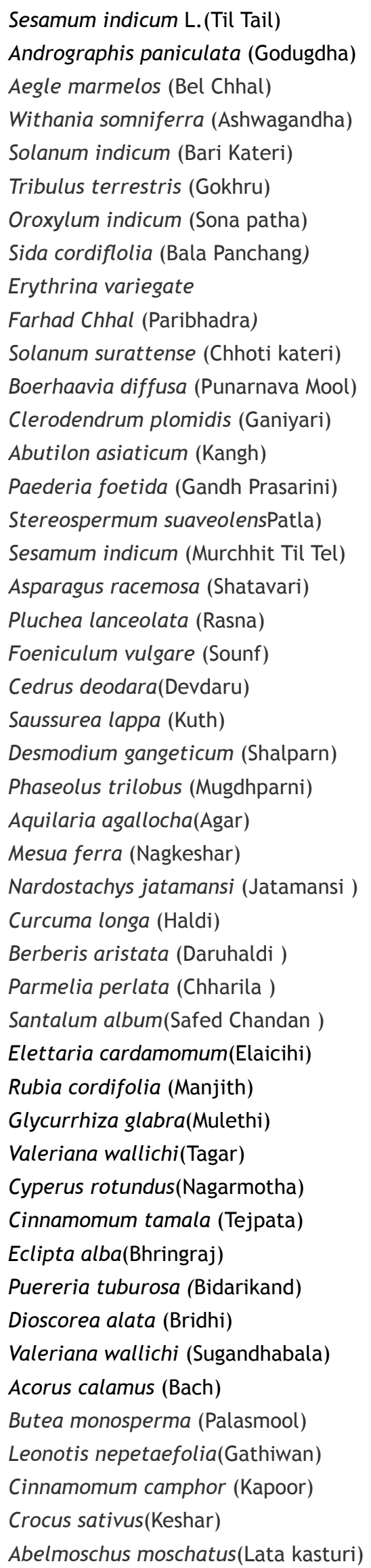


30. Saindhavadi taila
Patanjali Ayurved Limited, Haridwar, Uttarakhand - 249401, India.
Rock salt (Sandha Namak)

Calotropis gigantean (L.) Dryand. (Arka)

Piper nigrum L. (Kali Mirch)

Plumbago indica L. (Citrakamool)

Eclipta prostrate L. (Bhrngaraja)

Curcuma longa Linnaeus (Haldi)

Berberis aristata DC. (DaruHaldi)

Sesamum indicum L. (Til Taila) doses significantly suppressed granulomatous tissue formation in cotton pellet-induced granuloma test ${ }^{[126]}$.

The bioactive principles reported for anti-arthritic properties have been listed in Table 1 along with their respective plant source and mechanism of action. Also listed are the commercial anti-arthritic herbal products available in the market in Table 2. The compiled information regarding plants and their role in treatment of RA has been justified here as the perspective of plant derived medicine in the therapy of RA in near future.

\section{CONCLUSION}

In India, $45 \%$ rheumatic diseases patients are having comorbidities such as hypertension, hypothyroidism and diabetes mellitus. Hence, timely diagnosis of associated comorbid conditions is very much necessary for efficient management of rheumatic diseases. The presently available synthetic drugs used for management of rheumatic diseases have fatal side effect on prolonged uses. However, several medicinal plants and their bioactive phytochemicals exhibited potential responses on experimental rheumatic diseases. Several medicinal plants products (extracts/fractions) and their bioactive phytochemicals such as Epigallocatechin-3gallate exhibited inhibitory effect on the biomarkers namely TNF- $\alpha$, TFN- $\gamma$, NFK $\beta$, iNOS and COX which those are responsible for rheumatic diseases. In the present review, a list of medicinal plants reported for anti-arthritic properties, their bioactive phytochemicals and mechanism of action will be useful for research scholars, scientists, and industrialist. Though, several herbal formulations are available in market for management of RA and listed in the present review. But, there are huge scopes, for more and more research for invention of potent traditional knowledge based phyto-pharmaceutical drugs for treatment of RA.

\section{Conflict of interests:}

The authors declared no conflict of interest.

\section{REFERENCES}

1. Choudhary M, Kumar V, Malhotra H, Singh S. Medicinal plants with potential anti-arthritic activity. J Intercult Ethnopharmacol 2015;4(2):147.

2. Pandey P, Tiwari S. Therapeutic potential of Indian plants for the treatment of rheumatoid arthritis. J Pharmacogn Phytochem 2018;7(3):37-41.

3. Yadav V, Jayalakshmi S, Singla RK, Patra A, Khan S. Preliminary assessment of anti-inflammatory activity of Callicarpa macrophylla Vahl. leaves extracts. Indo Global J Pharma Sci 2011;1(3):219-22.

4. Centers for Disease Control and Prevention (CDC. Arthritis as a potential barrier to physical activity among adults with obesity-United States, 2007 and 2009. MMWR. Morbidity and mortality weekly report 2011;60(19):614.

5. Ward Y, Yap SF, Ravichandran V, Matsumura F, Ito M, Spinelli B, et al. The GTP binding proteins Gem and Rad are negative regulators of the Rho-Rho kinase pathway. J Cell Biol 2002;157(2):291-302.

6. Choudhary M, Kumar V, Gupta PK, Singh S. Anti-arthritic activity of Barleria prionitis Linn. leaves in acute and chronic models in Sprague Dawley rats. Bulletin of Faculty of Pharmacy, Cairo University 2014;52(2):199-209.

7. Makrides M, Best K, Yelland L, McPhee A, Zhou S, Quinlivan J, et al. A Randomized Trial of Prenatal n-3 Fatty Acid Supplementation and Preterm Delivery. N Engl J Med 2019;381(11):1035-45.

8. Harris Jr ED. Rheumatoid arthritis: pathophysiology and implications for therapy. N Engl J Med 1990;322(18):1277-89.

9. Chunxia C, Peng Z, Huifang P, Hanli R, Zehua H, Jizhou W. Extracts of Arisaema rhizomatum CEC Fischer attenuate inflammatory response on collagen-induced arthritis in BALB/c mice. J Ethnopharmacol 2011;133(2):573-82.

10. Ngoc DD, Catrina AI, Lundberg K, Harris HE, Ha NT, Anh PT, et al. Inhibition by Artocarpus tonkinensis of the development of collagen-induced arthritis in rats. Scand $\mathrm{J}$ Immunol 2005;61(3):234-41.

11. Chitme HR, Patel NP. Antiarthritis activity of Aristolochia bracteata extract in experimental animals. Open Nat Prod J 2009;2(1):6-15.

12. Nimesh S. Herbal drug is better than allopathic drug in the treatment of rheumatoid arthritis. Ind J Pharmacol 2018;5:53945.

13. Yassine EZ, Dalila B, El MansouriLatifa BS, Lebtar S, Sanae A, Abdellah F. Phytochemical Screening, Anti-inflammatory Activity and Acute Toxicity of Hydro-ethanolic, Flavonoid, Tannin and Mucilage Extracts of Lavandula stoechas L. from Morocco. Int J Pharm Phytochem Res 2016;8(1):31-7.

14. Cao H, Yu R, Choi Y, Ma ZZ, Zhang H, Xiang W, et al. Discovery of cyclooxygenase inhibitors from medicinal plants used to treat inflammation. Pharmacol Res 2010;61(6):519-24.

15. Lee J, Kim KA, Jeong S, Lee S, Park HJ, Kim NJ, et al. Anti-inflammatory, anti-nociceptive, and anti-psychiatric 
effects by the rhizomes of Alpinia officinarum on complete Freund's adjuvant-induced arthritis in rats. J Ethnopharmacol 2009;126(2):258-64.

16. Adebayo SA, Dzoyem JP, Shai LJ, Eloff JN. The antiinflammatory and antioxidant activity of 25 plant species used traditionally to treat pain in southern African. BMC Complement Altern Med 2015;15(1):159.

17. Guardia T, Rotelli AE, Juarez AO, Pelzer LE. Antiinflammatory properties of plant flavonoids. Effects of rutin, quercetin and hesperidin on adjuvant arthritis in rat. Farmaco 2001;56(9):683-7.

18. Bao J, Dai SM. A Chinese herb Tripterygium wilfordii Hook F in the treatment of rheumatoid arthritis: mechanism, efficacy, and safety. Rheumatol Int 2011;31(9):1123-9.

19. Ganju L, Karan D, Chanda S, Srivastava KK, Sawhney RC, Selvamurthy W. Immunomodulatory effects of agents of plant origin. Biomed Pharmacother 2003;57(7):296-300.

20. Efthimiou P, Kukar M. Complementary and alternative medicine use in rheumatoid arthritis: proposed mechanism of action and efficacy of commonly used modalities. Rheumatol Int 2010;30(5):571-86.

21. Adhikary R, Majhi A, Mahanti S, Bishayi B. Protective effects of methanolic extract of Adhatoda vasica Nees leaf in collageninduced arthritis by modulation of synovial toll-like receptor-2 expression and release of pro-inflammatory mediators. J Nutr Intermed Metab 2016 Mar 1;3:1.

22. Gautam R, Jachak SM, Saklani A. Anti-inflammatory effect of Ajuga bracteosa Wall Ex Benth. mediated through cyclooxygenase (COX) inhibition. J Ethnopharmacol 2011;133(2):928-30.

23. Kaithwas G, Gautam R, Jachak SM, Saklani A. Antiarthritic effects of Ajuga bracteosa Wall ex Benth. in acute and chronic models of arthritis in albino rats. Asian Pac J Trop Biomed 2012;2(3):185-8.

24. Ameri A. The effects of Aconitum alkaloids on the central nervous system. Prog Neurobiol 1998;56(2):211-35.

25. Jabeen N, Shawl AS, Dar GH, Sultan P. Callus induction and organogenesis from explants of Aconitum heterophyllum medicinal plant. Biotechnol 2006;5(3):287-91.

26. Zhao KJ, Dong TT, Tu PF, Song ZH, Lo CK, Tsim KW. Molecular genetic and chemical assessment of radix Angelica (Danggui) in China. J Agric Food Chem 2003;51(9):2576-83.

27. Xu Q, Zhou Y, Zhang R, Sun Z, Cheng LF. Antiarthritic activity of Qi-Wu rheumatism granule (a Chinese herbal compound) on complete Freund's adjuvant-induced arthritis in rats. Evid Based Complement Alternat Med 2017;2017:1960517.

28. Park G, Lee SH, Han JY, Oh DS. Altered TNF- $\alpha$ response by Aconibal $^{\circledR}$ and methotrexate in a lipopolysaccharide-induced setting of inflammatory conditions: Potential on a synergistic combination. J Ethnopharmacol 2018;213:191-7.

29. Wei WL, Zeng R, Gu CM, Qu Y, Huang LF. Angelica sinensis in China-A review of botanical profile, ethnopharmacology, phytochemistry and chemical analysis. J Ethnopharmacol 2016;190:116-41.

30. Hook ILI. Danggui to Angelica sinensis root: Are potential benefits to European women lost in translation? A review. J Ethnopharmacol 2014;152(1):1-13.

31. Zhao KJ, Dong TT, Tu PF, Song ZH, Lo CK, Tsim KW. Molecular genetic and chemical assessment of radix Angelica (Danggui) in China. J Agric Food Chem 2003;51(9):2576-83.

32. Wang YL, Liang YZ, Chen BM, He YK, Li BY, Hu QN. LC-DAD-APCI-MS-based screening and analysis of the absorption and metabolite components in plasma from a rabbit administered an oral solution of danggui. Anal Bioanal Chem 2005;383(2):247-54.

33. Dong ZB, Li SP, Hong M, Zhu Q. Hypothesis of potential active components in Angelica sinensis by using biomembrane extraction and high performance liquid chromatography. J Pharma Biomed Anal 2005;38(4):664-9.

34. Lee WS, Lim JH, Sung MS, Lee EG, Oh YJ, Yoo WH. Ethyl acetate fraction from Angelica sinensis inhibits IL-1 $\beta$-induced rheumatoid synovial fibroblast proliferation and COX-2, PGE2, and MMPs production. Biol Res 2014;47(1):41.

35. Magdalou J, Chen LB, Wang H, Qin J, Wen Y, Li XJ, et al. Angelica sinensis and osteoarthritis: a natural therapeutic link? Biomed Mater Eng 2015;25(s1):179-86.

36. Lee WY, Chen HY, Chen KC, Chen CY. Treatment of rheumatoid arthritis with traditional Chinese medicine. BioMed Res Int 2014;2014:528018.

37. Khadse CD, Kakde RB. Anti-inflammatory activity of aqueous extract fractions of Barleria prionitis L roots. Asian J Plant Sci Res 2011;1(2):63-8.

38. Duke JA. Handbook of medicinal herbs. CRC press; 2002.

39. Yashwanth BM, Rai SS, Gowda KS. Effect of Bryonia alba homeopathic formulation in mono sodium urate induced gouty arthritis and potassium oxonate induced hyperuricemia in experimental animals. World J Pharm Pharm Sci 2014;4:112034.

40. Patil KR, Patil CR, Jadhav RB, Mahajan VK, Patil PR, Gaikwad PS. Anti-arthritic activity of bartogenic acid isolated from fruits of Barringtonia racemosa Roxb.(Lecythidaceae). Evid Based Complement Alternat Med 2011;2011:785245.

41. Çitoğlu GS, Acıkara ÖB, Yılmaz BS, Özbek H. Evaluation of analgesic, anti-inflammatory and hepatoprotective effects of lycorine from Sternbergia fisheriana (Herbert) Rupr. Fitoterapia 2012;83(1):81-7.

42. Kim YH, Kim KH, Han CS, Park SH, Yang HC, Lee BY, et al. Anti-inflammatory activity of Crinum asiaticum Linne var. japonicum extract and its application as a cosmeceutical ingredient. J Cosmet Sci 2008;59(5):419-30.

43. Rahman MA, Sharmin R, Uddin MN, Rana MS, Ahmed NU. Antibacterial, antioxidant and cytotoxic properties of Crinum asiaticum bulb extract. Banglad J Microbiol 2011;28(1):1-5.

44. Rahman MA, Hossain SA, Ahmed NU, Islam MS. Analgesic and anti-inflammatory effects of Crinum asiaticum leaf alcoholic extract in animal models. African $\mathrm{J}$ Biotechnol 2013;12(2):212-8.

45. Samud AM, Asmawi MZ, Sharma JN, Yusof AP. Antiinflammatory activity of Crinum asiaticum plant and its effect on bradykinin-induced contractions on isolated uterus. Immunopharmacol 1999;43(2-3):311-6.

46. He Y, Yue Y, Zheng X, Zhang K, Chen S, Du Z. Curcumin, inflammation, and chronic diseases: how are they linked? Molecules 2015;20(5):9183-213.

47. Heger M, van Golen RF, Broekgaarden M, Michel MC. The molecular basis for the pharmacokinetics and pharmacodynamics of curcumin and its metabolites in relation to cancer. Pharmacol Rev 2014;66(1):222-307.

48. Wang YJ, Pan MH, Cheng AL, Lin LI, Ho YS, Hsieh CY, et al. Stability of curcumin in buffer solutions and characterization of its degradation products. J Pharma Biomed Anal 1997;15(12):1867-76.

49. Zahidah A, Faizah O, Nur Aqilah K, Taty Anna K. Curcumin as an Anti-Arthritic Agent in Collagen-Induced Arthritic Sprague-Dawley Rats. Sains Malaysiana 2012;41(5):591-5. 
50. Srimal RC, Dhawan BN. Pharmacology of diferuloyl methane (curcumin), a non-steroidal anti-inflammatory agent. J Pharma Pharmacol 1973;25(6):447-52.

51. Dcodhar SD, Sethi R, Srimal RC. Preliminary study on antirheumatic activity of curcumin (diferuloyl methane). Ind $\mathrm{J}$ Med Res 2013;138(1):632-634.

52. Hamidpour R, Hamidpour S, Hamidpour M, Sohraby M, Hamidpour M. Turmeric (Curcuma longa): from a variety of traditional medicinal applications to its novel roles as active antioxidant, anti-inflammatory, anti-cancer, and anti-diabetes. Int J Pharmacol Phytochem Ethnomed 2015;1:37-45.

53. Jurenka JS. Anti-inflammatory properties of curcumin, a major constituent of Curcuma longa: a review of preclinical and clinical research. Altern Med Rev 2009;14(2):141-53.

54. Funk JL, Oyarzo JN, Frye JB, Chen G, Lantz RC, Jolad SD, et al. Turmeric extracts containing curcuminoids prevent experimental rheumatoid arthritis. J Nat Prod 2006;69(3):351-5.

55. Enas AK. Study of the possible protective and therapeutic influence of coriander (Coriandrum sativum L.) against neurodegenerative disorders and Alzheimer's disease induced by aluminum chloride in cerebral cortex of male albino rats. Nat Sci 2010;8(11):202-13.

56. Nair V, Singh S, Gupta YK. Evaluation of disease modifying activity of Coriandrum sativum in experimental models. Ind J Med Res 2012;135(2):240.

57. Rajeshwari U, Andallu B. Medicinal benefits of coriander (Coriandrum sativum L). Spatula DD 2011;1(1):51-8.

58. Nair V, Singh S, Gupta YK. Anti-granuloma activity of Coriandrum sativum in experimental models. J Ayurveda Integr Med 2013;4(1):13.

59. Singh MK, Khare G, Iyer SK, Sharwan G, Tripathi DK. Clerodendrum serratum: A clinical approach. J Appl Pharm Sci 2012;2(2):11-5.

60. Shareef IM, Leelavathi S, Gopinath SM. Evaluation of in vivo Activity of Clerodendrum serratum L. against Rheumatism. Int J Innovat Res Sci Eng Technol 2013;2(12):7750-8.

61. Wilson E, Rajamanickam G, Vyas N, Agarwal A, Dubey G. Herbs used in Siddha medicine for arthritis- A review. Indian J Tradit Knowl 2007;6(4):678-86.

62. Solapure P, Pradeep RM, Hegde PL. Comparative antiinflammatory activity of Clerodendrum serratum (Linn) Moon and Solanum xanthocarpum Schrad and Wendl in wistar ablino rats. J Phytopharmacol 2016;5(2):38-44.

63. El-Far AH, Shaheen HM, Alsenosy AW, El-Sayed YS, Al Jaouni SK, Mousa SA. Costus speciosus: Traditional Uses, Phytochemistry, and Therapeutic Potentials. Pharmacogn Revi 2018;12(23):120-7.

64. Srivastava S, Singh P, Jha KK, Mishra G, Srivastava S, Khosa RL. Evaluation of anti-arthritic potential of the methanolic extract of the aerial parts of Costus speciosus. J Ayurveda Integr Med 2012;3(4):204.

65. Chaudhary AK, Ahmad S, Mazumder A. Cedrus deodara (Roxb.) Loud.: a review on its ethnobotany, phytochemical and pharmacological profile. Pharmacogn J 2011;3(23):12-7.

66. Shinde UA, Phadke AS, Nair AM, Mungantiwar AA, Dikshit VJ, Saraf MN. Studies on the anti-inflammatory and analgesic activity of Cedrus deodara (Roxb.) Loud. wood oil. J Ethnopharmacol 1999;65(1):21-7.

67. Gupta S, Gupta A, Gupta AK, Pakash D. In vitro Antiarthritic activity of ethanolic extracts of Callicarpa macrophyall flower. Int Res J Pharm 2013;4(3):160-2.

68. Marzouk B, Marzouk Z, Haloui E, Turki M, Bouraoui A, Aouni $\mathrm{M}$, et al. Anti-inflammatory evaluation of immature fruit and seed aqueous extracts from several populations of Tunisian Citrullus colocynthis Schrad. African J Biotechnol 2011;10(20):4217-25.

69. Biswal B. Standardization protocol development of hydroalcoholic extract of fruits of Citrullus Colocynthis against anti-arthritic activity. Int J Green Pharm 2016;10(1):59-63.

70. Rathi B, Bodhankar S, Mohan V, Thakurdesai P. Ameliorative effects of a polyphenolic fraction of Cinnamomum zeylanicum L. bark in animal models of inflammation and arthritis. Sci Pharm 2013;81(2):567-90.

71. Ahmad F, Khan RA, Rasheed S. Preliminary screening of methanolic extracts of Celastrus paniculatus and Tecomella undulata for analgesic and anti-inflammatory activities. J Ethnopharmacol 1994;42(3):193-8.

72. Shashank D, Rajendra SV, Mistry A. An overview of Phytoconstituents and Pharmacological Activities of Celastrus paniculatus Willd. J Pharm Res 2018;16(4):307-13.

73. Pracheta SV, Paliwal R, Sharma S. In vitro free radical scavenging and antioxidant potential of ethanolic extract of Euphorbia neriifolia Linn. Int J Pharm Pharm Sci 2011;3(1):238-42.

74. Kirtikar KR. Indian Medicinal Plants: By KR Kirtikar, BD Basu, and ICS. Sudhindra Nath Basu; 1918.

75. Chandrasenan P, Neethu MV, Anjumol VM, Anandan V, Selvaraj R. Triterpenoid fraction isolated from Euphorbia tirucalli Linn. ameliorates collagen induced arthritis in Wistar rats. J App Pharm Sci 2016;6(1):70-5.

76. Bani S, Kaul A, Khan B, Gupta VK, Satti NK, Suri KA, et al. Anti-arthritic activity of a biopolymeric fraction from Euphorbia tirucalli. J Ethnopharmacol 2007;110(1):92-8.

77. Zuzarte M, Gonçalves MJ, Cavaleiro C, Cruz MT, Benzarti A, Marongiu B, et al. Antifungal and anti-inflammatory potential of Lavandula stoechas and Thymus herba-barona essential oils. Industrial Crops Prod 2013 Jan 1;44:97-103.

78. Algieri F, Rodriguez-Nogales A, Vezza T, Garrido-Mesa J, Garrido-Mesa N, Utrilla MP, et al. Anti-inflammatory activity of hydroalcoholic extracts of Lavandula dentata L. and Lavandula stoechas L. J Ethnopharmacol 2016;190:142-58.

79. Mahajan SG, Mali RG, Mehta AA. Protective effect of ethanolic extract of seeds of Moringa oleifera Lam. against inflammation associated with development of arthritis in rats. $\mathbf{J}$ Immunotoxicol 2007;4(1):39-47.

80. Kumar V, Verma A, Ahmed D, Sachan NK, Anwar F, Mujeeb M. Fostered antiarthritic upshot of Moringa oleifera lam. stem bark extract in diversely induced arthritis in wistar rats with plausible mechanism. Int J Pharm Sci Res 2013;4(10):3894.

81. Mohanty RB, Panda T, Tripathy BK. Medicinal rice varieties of India need urgent attention. Curr Sci 2012;102(4):25.

82. Boominathan M, Bakiyalakshmi SV. In Vitro anti arthritic activity of Njavara rice. Asian J Pharm Res 2016;6(4):250-2.

83. Rahman $\mathrm{H}$, Eswaraiah MC, Vakati $\mathrm{K}$, Madhavi P. In vitro studies suggest probable mechanism of eucalyptus oil for antiinflammatory and anti-arthritic activity. Int J Phyto Pharm 2012;2:81-3.

84. Vane JR, Botting RM. New insights into the mode of action of anti-inflammatory drugs. Inflamm Res 1995;44(1):1-0.

85. Agrawal SS, Paridhavi M. Herbal drug technology. Hyderabad: Universities Press Private Limited; 2007.

86. Mohanlal S, Parvathy R, Shalini V, Mohanan R, Helen A, Jayalekshmy A. Chemical indices, antioxidant activity and anti-inflammatory effect of extracts of the medicinal rice "njavara" and staple varieties: a comparative study. J Food Biochem 2013;37(3):369-80. 
87. Pandey A, Bani S, Shah B. Pinitol: a novel compound with anti-arthritic effect in pre-clinical study. Int $\mathrm{J}$ Rheumat Dis 2010;13:16.

88. Bang JS, Choi HM, Sur BJ, Lim SJ, Kim JY, Yang HI, et al. Anti-inflammatory and antiarthritic effects of piperine in human interleukin $1 \beta$-stimulated fibroblast-like synoviocytes and in rat arthritis models. Arthritis Res Ther 2009;11(2):1-9.

89. Rajendran R, Krishnakumar E. Anti-arthritic activity of Premna serratifolia Linn., wood against adjuvant induced arthritis. Avicenna J Med Biotechnol 2010;2(2):101.

90. Mei H, Zuo S, Ye L, Wang J, Ma S. Review of the application of the traditional Chinese medicinal herb, Ranunculus sceleratus Linn. J Med Plant Res 2012;6(10):1821-6.

91. Aslam MS, Choudhary BA, Uzair M, Ijaz AS. The genus Ranunculus: a phytochemical and ethnopharmacological review. Int J Pharm Pharm Sci 2012;4(5):15-22.

92. Prieto JM, Recio MC, Giner RM, Máñez S, Rios JL. Pharmacological approach to the pro-and anti-inflammatory effects of Ranunculus sceleratus L. J Ethnopharmacol 2003;89(1):131-7.

93. Patel Ritesh G, Pathak Nimish L, Rathod Jaimik D, LD P, Bhatt Nayna M. Phytopharmacological properties of Randia dumetorum as a potential medicinal tree: an overview. J Appl Pharm Sci 2011;1(10):24-6.

94. Patel RG, Pathak NL, Rathod JD, Jivani DN, Thaker RU, Bhatt NM. Anti-Arthritic and Anti-Inflammatory Activity of Methanolic Extract of Randia Dumetorum Fruits In Freund ${ }^{\text {ee }}$ s Complete Adjuvant Induced Arthritis. World J Pharm sci 2012;1(2):309-25.

95. Saneja A, Kaushik P, Kaushik D, Kumar S, Kumar D. Antioxidant, analgesic and anti-inflammatory activities of Santalum album Linn. Plant Med 2009;75(4):102.

96. Gupta A, Chaphalkar SR. Anti-inflammatory and immunosuppressive activities of flavonoids from medicinal plants. J Herb Med Pharmacol 2016;5(3):120-4.

97. González AG, Andrés LS, Aguiar ZE, Luis JG. Diterpenes from Salvia mellifera and their biogenetic significance. Phytochem 1992;31(4):1297-305.

98. Gupta SR, Nirmal SA, Patil RY, Asane GS. Anti-arthritic activity of various extracts of Sida rhombifolia aerial parts. Nat Prod Res 2009;23(8):689-95.

99. Narendhirakannan RT, Limmy TP. Anti-inflammatory and anti-oxidant properties of Sida rhombifolia stems and roots in adjuvant induced arthritic rats. Immunopharmacol Immunotoxicol 2012;34(2):326-36.

100. Banerjee S, Sur TK, Mandal S, Das PC, Sikdar S. Assessment of the anti-inflammatory effects of Swertia chirata in acute and chronic experimental models in male albino rats. Ind $\mathbf{J}$ Pharmacol 2000;32(1):21-4.

101. Sur TK, Banerjee S, Sur K, Mandal S, Das C, Sikdar S. Assessment of the anti-inflammatory effect of Swertia chirata in acute and chronic experimental models in male albino rats DST-WB View project Nanoparticle Modified Dye-sensitized Solar Cell: Toward Renewable and Sustainable Energy Source for Bangladesh. Ind J Pharmacol 2000;1(1):21-4.

102. Ghosal S, Sharma PV, Chaudhuri RK, Bhattacharya SK. Chemical constituents of the gentianaceae V: Tetraoxygenated xanthones of Swertia chirata buch.-ham. J Pharm Sci 1973;62(6):926-30.

103. Ghosal S, Sharma PV, Jaiswal DK. Chemical constituents of gentianaceae XXIII: tetraoxygenated and pentaoxygenated xanthones and xanthone O-glucosides of Swertia angustifolia Buch.-Ham. J Pharm Sci 1978;67(1):55-60.
104. Sirish Kumar IV, Paul BN, Asthana R, Saxena A, Mehrotra S, Rajan G. Swertia chirayita Mediated Modulation of Interleukin-1 $\beta$ Interleukin-6, Interleukin-10, Interferon- $\gamma$, and Tumor Necrosis Factor- $\alpha$ in Arthritic Mice. Immunopharmacol Immunotoxicol 2003;25(4):573-83.

105. Kumar EK, Mastan SK, Reddy KR, Reddy GA, Raghunandan $\mathrm{N}$, Chaitanya G. Anti-arthritic property of the methanolic extract of Syzygium cumini seeds. Int J Integr Biol 2008;4(1):55-61.

106. Venkataramanan RV, Chitra V, Raju D, Sumithra M, Prakash MP, Goswami H. Evaluation of Antirheumatic Activity of Petroleum Ether Extract of Syzygium cumini Stem Bark in Rats. Biomed Pharmacol J 2016;9(2):639-42.

107. Soeken KL, Miller SA, Ernst E. Herbal medicines for the treatment of rheumatoid arthritis: a systematic review. Rheumatology 2003;42(5):652-9.

108. Wang HL, Jiang Q, Feng XH, Zhang HD, Ge L, Luo CG, et al. Tripterygium wilfordii Hook $\mathrm{F}$ versus conventional synthetic disease-modifying anti-rheumatic drugs as monotherapy for rheumatoid arthritis: a systematic review and network metaanalysis. BMC Complement Alternat Med 2016;16(1):215.

109. Lipsky PE, Tao XL. A potential new treatment for rheumatoid arthritis: thunder god vine. In: Seminars in arthritis and rheumatism 1997;26(5):713-23.

110. Tao X, Younger J, Fan FZ, Wang B, Lipsky PE. Benefit of an extract of Tripterygium Wilfordii Hook $\mathrm{F}$ in patients with rheumatoid arthritis: A double-blind, placebo-controlled study. Arthritis Rheum 2002;46(7):1735-43.

111. Wang X, Zu Y, Huang L, Yu J, Zhao H, Wen C, et al. Treatment of rheumatoid arthritis with combination of methotrexate and Tripterygium wilfordii: a meta-analysis. Life Sci 2017;171:4550.

112. Asgarpanah J, Mohajerani R. Phytochemistry and pharmacologic properties of Urtica dioica L. J Med Plant Res 2012;6(46):5714-9.

113. Chrubasik S, Enderlein W, Bauer R, Grabner W. Evidence for antirheumatic effectiveness of Herba Urticae dioicae in acute arthritis: A pilot study. Phytomedicine 1997;4(2):105-8.

114. Riehemann K, Behnke B, Schulze-Osthoff K. Plant extracts from stinging nettle (Urtica dioica), an antirheumatic remedy, inhibit the proinflammatory transcription factor NF- $\mathrm{kB}$. FEBS lett 1999;442(1):89-94.

115. Gupta A, Singh S. Evaluation of anti-inflammatory effect of Withania somnifera root on collagen-induced arthritis in rats. Pharm Biol 2014;52(3):308-20.

116. Singh D, Aggarwal A, Maurya R, Naik S. Withania somnifera inhibits NF- $\kappa \mathrm{B}$ and AP-1 transcription factors in human peripheral blood and synovial fluid mononuclear cells. Phytother Res 2007;21(10):905-13.

117. Ganesan K, Sehgal PK, Mandal AB, Sayeed S. Protective effect of Withania somnifera and Cardiospermum halicacabum extracts against collagenolytic degradation of collagen. Appl Biochem Biotechnol 2011;165(3-4):1075-91.

118. Patil D, Gautam M, Jadhav U, Mishra S, Karupothula S, Gairola $\mathrm{S}$, et al. Physicochemical stability and biological activity of Withania somnifera extract under real-time and accelerated storage conditions. Planta Med 2010;76(05):481-8.

119. Al-Nahain A, Jahan R, Rahmatullah M. Zingiber officinale: a potential plant against rheumatoid arthritis. Arthritis 2014;2014:1-8.

120. Mascolo N, Jain R, Jain SC, Capasso F. Ethnopharmacologic investigation of ginger (Zingiber officinale). J Ethnopharmacol 1989;27(1-2):129-40. 
121. Kiuchi F, Shibuya M, Sankawa U. Inhibitors of prostaglandin biosynthesis from ginger. Chemical and pharmaceutical bulletin 1982;30(2):754-7.

122. Thomson M, Al-Qattan KK, Al-Sawan SM, Alnaqeeb MA, Khan I, Ali M. The use of ginger (Zingiber officinale Rosc.) as a potential anti-inflammatory and antithrombotic agent. Prostaglandins Leukot Essent Fatty Acids 2002;67(6):475-8.

123. Pragasam SJ, Kumar S, Bhoumik M, Sabina EP, Rasool M. 6-Gingerol, an active ingredient of ginger suppresses monosodium ureate crystal-induced inflammation: An in vivo and in vitro evaluation. Ann Biol Res 2011;2:200-8.
124. Zakaria ZA, Mohamad AS, Ahmad MS, Mokhtar AF, Israf DA, Lajis NH, et al. Preliminary analysis of the anti-inflammatory activity of essential oils of Zingiber zerumbet. Biol Res Nurs 2011;13(4):425-32.

125. Chien TY, Chen LG, Lee CJ, Lee FY, Wang CC. Antiinflammatory constituents of Zingiber zerumbet. Food Chem 2008;110(3):584-9.

126. Sulaiman MR, Perimal EK, Akhtar MN, Mohamad AS, Khalid $\mathrm{MH}$, Tasrip NA, et al. Anti-inflammatory effect of zerumbone on acute and chronic inflammation models in mice. Fitoterapia 2010;81(7):855-8. 